\title{
ON THE TRIPLE HIERARCHICAL VARIATIONAL INEQUALITIES WITH CONSTRAINTS OF MIXED EQUILIBRIA, VARIATIONAL INCLUSIONS AND SYSTEMS OF GENERALIZED EQUILIBRIA
}

\author{
LU-CHUAN CENG AND JEN-CHIH YAO
}

\begin{abstract}
In this paper, we introduce and analyze a relaxed iterative algorithm by combining Korpelevich's extragradient method, hybrid steepest-descent method and Mann's iteration method. It is proven that under appropriate assumptions, the proposed algorithm converges strongly to a common element of the fixed point set of infinitely many nonexpansive mappings, the solution set of a generalized mixed equilibrium problem (GMEP), the solution set of finitely many variational inclusions and the solution set of a system of generalized equilibrium problems (SGEP), which is just a unique solution of a triple hierarchical variational inequality (THVI) in a real Hilbert space. In addition, we also consider the application of the proposed algorithm to solving a hierarchical variational inequality problem with constraints of the GMEP, the SGEP and finitely many variational inclusions.
\end{abstract}

\section{Introduction}

Let $H$ be a real Hilbert space with inner product $\langle\cdot, \cdot\rangle$ and norm $\|\cdot\|, C$ be a nonempty closed convex subset of $H$ and $P_{C}$ be the metric projection of $H$ onto $C$. Let $S: C \rightarrow H$ be a nonlinear mapping on $C$. We denote by $\operatorname{Fix}(S)$ the set of fixed points of $S$ and by $\mathbf{R}$ the set of all real numbers. A mapping $S: C \rightarrow H$ is called $L$-Lipschitz continuous if there exists a constant $L>0$ such that

$$
\|S x-S y\| \leq L\|x-y\|, \quad \forall x, y \in C .
$$

In particular, if $L=1$ then $S$ is called a nonexpansive mapping; if $L \in(0,1)$ then $S$ is called a contraction.

Received May 4, 2014, accepted May 5, 2014.

2010 Mathematics Subject Classification. 49J30, 47H09, 47J20, 49M05.

Key words and phrases. Hybrid steepest-descent method, generalized mixed equilibrium problem, system of generalized equilibrium problems, variational inclusion, nonexpansive mapping, fixed Point. Corresponding author: Jen-Chih Yao.

This research was partially supported by the National Science Foundation of China (11071169), Innovation Program of Shanghai Municipal Education Commission (09ZZ133) and Ph.D. Program Foundation of Ministry of Education of China (20123127110002).

This research was partially supported by the grant NSC 103-2923-E-037-001-MY3. 
Let $A: C \rightarrow H$ be a nonlinear mapping on $C$. We consider the following variational inequality problem (VIP): find a point $x \in C$ such that

$$
\langle A x, y-x\rangle \geq 0, \quad \forall y \in C .
$$

The solution set of VIP (1.1) is denoted by $\operatorname{VI}(C, A)$.

The VIP (1.1) was first discussed by Lions [13] and now is well known; there are a lot of different approaches towards solving VIP (1.1) in finite-dimensional and infinite-dimensional spaces, and the research is intensively continued. It is well known that, if $A$ is a strongly monotone and Lipschitz-continuous mapping on $C$, then VIP (1.1) has a unique solution.

In 1976, Korpelevich [2] proposed an iterative algorithm for solving the VIP (1.1) in Euclidean space $\mathbf{R}^{n}$ :

$$
\left\{\begin{array}{l}
y_{n}=P_{C}\left(x_{n}-\tau A x_{n}\right), \\
x_{n+1}=P_{C}\left(x_{n}-\tau A y_{n}\right), \quad \forall n \geq 0,
\end{array}\right.
$$

with $\tau>0$ a given number, which is known as the extragradient method. The literature on the VIP is vast and Korpelevich's extragradient method has received great attention given by many authors, who improved it in various ways; see e.g., [8, 9, 10, 11, 12, 14, 18, 20, 23, 24, 25, $28,29,30,34,35,36]$ and references therein, to name but a few.

Let $\varphi: C \rightarrow \mathbf{R}$ be a real-valued function, $A: H \rightarrow H$ be a nonlinear mapping and $\Theta$ : $C \times C \rightarrow \mathbf{R}$ be a bifunction. In 2008, Peng and Yao [23] introduced the following generalized mixed equilibrium problem (GMEP) of finding $x \in C$ such that

$$
\Theta(x, y)+\varphi(y)-\varphi(x)+\langle A x, y-x\rangle \geq 0, \quad \forall y \in C .
$$

We denote the set of solutions of $\operatorname{GMEP}(1.2)$ by $\operatorname{GMEP}(\Theta, \varphi, A)$. The GMEP (1.2) is very general in the sense that it includes, as special cases, optimization problems, variational inequalities, minimax problems, Nash equilibrium problems in noncooperative games and others. The GMEP is further considered and studied; see e.g., [20, 25, 26, 29, 36].

In particular, if $A=0$, then GMEP (1.2) reduces to the mixed equilibrium problem (MEP) which is to find $x \in C$ such that

$$
\Theta(x, y)+\varphi(y)-\varphi(x) \geq 0, \quad \forall y \in C .
$$

It was considered and studied in $[15,21]$. The set of solutions of the above MEP is denoted by $\operatorname{MEP}(\Theta, \varphi)$.

In [23], Peng and Yao assumed that $\Theta: C \times C \rightarrow \mathbf{R}$ is a bifunction satisfying conditions (H1) $-(\mathrm{H} 4)$ and $\varphi: C \rightarrow \mathbf{R}$ is a lower semicontinuous and convex function with restriction (H5), where 
(H1) $\Theta(x, x)=0$ for all $x \in C$;

(H2) $\Theta$ is monotone, i.e., $\Theta(x, y)+\Theta(y, x) \leq 0$ for any $x, y \in C$;

(H3) $\Theta$ is upper-hemicontinuous, i.e., for each $x, y, z \in C$,

$$
\limsup _{t \rightarrow 0^{+}} \Theta(t z+(1-t) x, y) \leq \Theta(x, y)
$$

(H4) $\Theta(x, \cdot)$ is convex and lower semicontinuous for each $x \in C$;

(H5) for each $x \in H$ and $r>0$, there exists a bounded subset $D_{x} \subset C$ and $y_{x} \in C$ such that for any $z \in C \backslash D_{x}$,

$$
\Theta\left(z, y_{x}\right)+\varphi\left(y_{x}\right)-\varphi(z)+\frac{1}{r}\left\langle y_{x}-z, z-x\right\rangle<0 .
$$

Given a positive number $r>0$. Let $S_{r}^{(\Theta, \varphi)}: H \rightarrow C$ be the solution set of the auxiliary mixed equilibrium problem, that is, for each $x \in H$,

$$
S_{r}^{(\Theta, \varphi)}(x):=\left\{y \in C: \Theta(y, z)+\varphi(z)-\varphi(y)+\frac{1}{r}\left\langle K^{\prime}(y)-K^{\prime}(x), z-y\right\rangle \geq 0, \forall z \in C\right\},
$$

where $K$ is a Fréchet differential and strongly convex function on $H$. In particular, whenever $K(x)=\frac{1}{2}\|x\|^{2}, \forall x \in H, S_{r}^{(\Theta, \varphi)}$ is rewritten as $T_{r}^{(\Theta, \varphi)}$.

Let $\Theta_{1}, \Theta_{2}: C \times C \rightarrow \mathbf{R}$ be two bifunctions, and $A_{1}, A_{2}: C \rightarrow H$ be two nonlinear mappings. Consider the following system of generalized equilibrium problems (SGEP): find $\left(x^{*}, y^{*}\right) \in$ $C \times C$ such that

$$
\begin{cases}\Theta_{1}\left(x^{*}, x\right)+\left\langle A_{1} y^{*}, x-x^{*}\right\rangle+\frac{1}{v_{1}}\left\langle x^{*}-y^{*}, x-x^{*}\right\rangle \geq 0, & \forall x \in C, \\ \Theta_{2}\left(y^{*}, y\right)+\left\langle A_{2} x^{*}, y-y^{*}\right\rangle+\frac{1}{v_{2}}\left\langle y^{*}-x^{*}, y-y^{*}\right\rangle \geq 0, & \forall y \in C,\end{cases}
$$

where $v_{1}>0$ and $v_{2}>0$ are two constants. It was introduced and studied in [24]. Whenever $\Theta_{1} \equiv \Theta_{2} \equiv 0$, the SGEP reduces to a system of variational inequalities, which was considered and studied in $[9,10,30]$. It is worth to mention that the system of variational inequalities is a tool to solve the Nash equilibrium problem for noncooperative games.

Let $f: H \rightarrow H$ be a contraction and $V: H \rightarrow H$ be a bounded linear operator, which is strongly positive, i.e., there exists a constant $\bar{\gamma} \in(0,1]$ such that $\langle V x, x\rangle \geq \bar{\gamma}\|x\|^{2}, \forall x \in H$. Assume that $\varphi: H \rightarrow \mathbf{R}$ is a lower semicontinuous and convex functional, that $\Theta, \Theta_{1}, \Theta_{2}: H \times H \rightarrow$ $\mathbf{R}$ satisfy conditions (H1)-(H4), and that $A, A_{1}, A_{2}: H \rightarrow H$ are inverse-strongly monotone. Put $G:=T_{v_{1}}^{\Theta_{1}}\left(I-v_{1} A_{1}\right) T_{v_{2}}^{\Theta_{2}}\left(I-v_{2} A_{2}\right)$. For the case of $C=H$, Ceng, Ansari and Schaible [25] introduced the following hybrid extragradient-like iterative algorithm

$$
\left\{\begin{array}{l}
z_{n}=S_{r_{n}}^{(\Theta, \varphi)}\left(x_{n}-r_{n} A x_{n}\right), \\
x_{n+1}=\alpha_{n}\left(u+\gamma f\left(x_{n}\right)\right)+\beta_{n} x_{n}+\left(\left(1-\beta_{n}\right) I-\alpha_{n}(I+\mu V)\right) W_{n} G z_{n}, \quad \forall n \geq 0,
\end{array}\right.
$$


for finding a common solution of GMEP (1.2), SGEP (1.3) and the fixed point problem of infinitely many nonexpansive mappings $\left\{T_{n}\right\}_{n=1}^{\infty}$ on $H$, where $\left\{r_{n}\right\} \subset(0, \infty),\left\{\alpha_{n}\right\},\left\{\beta_{n}\right\} \subset(0,1), v_{k} \in$ $\left(0,2 \zeta_{k}\right), k=1,2, x_{0}, u \in H$ are given, and $W_{n}$ is the $W$-mapping generated by $T_{n}, T_{n-1}, \ldots, T_{1}$ and $\lambda_{n}, \lambda_{n-1}, \ldots, \lambda_{1} \in(0, b]$ for some $b \in(0,1)$ (see (2.2) in Sect. 2). The authors proved the strong convergence of the sequence $\left\{x_{n}\right\}$ generated by (1.4) to a point $x^{*} \in \Omega:=\cap_{n=1}^{\infty} \operatorname{Fix}\left(T_{n}\right) \cap$ $\operatorname{GMEP}(\Theta, \varphi, A) \cap \operatorname{SGEP}(G)$ under some suitable conditions, where $\operatorname{SGEP}(G)$ is the fixed point set of the mapping $G$.

On the other hand, let $B$ be a single-valued mapping of $C$ into $H$ and $R$ be a set-valued mapping with $D(R)=C$. Consider the following variational inclusion: find a point $x \in C$ such that

$$
0 \in B x+R x .
$$

We denote by $\mathrm{I}(B, R)$ the solution set of the variational inclusion (1.5). In particular, if $B=R=$ 0 , then $\mathrm{I}(B, R)=C$. If $B=0$, then problem (1.5) becomes the inclusion problem introduced by Rockafellar [5]. It is known that problem (1.5) provides a convenient framework for the unified study of optimal solutions in many optimization related areas including mathematical programming, complementarity problems, variational inequalities, optimal control, mathematical economics, equilibria and game theory, etc. Let a set-valued mapping $R: D(R) \subset H \rightarrow 2^{H}$ be maximal monotone. We define the resolvent operator $J_{R, \lambda}: H \rightarrow \overline{D(R)}$ associated with $R$ and $\lambda$ as follows:

$$
J_{R, \lambda}=(I+\lambda R)^{-1}, \quad \forall x \in H
$$

where $\lambda$ is a positive number.

In 1998, Huang [33] studied problem (1.5) in the case where $R$ is maximal monotone and $B$ is strongly monotone and Lipschitz continuous with $D(R)=C=H$. Subsequently, Zeng, Guu and Yao [7] further studied problem (1.5) in the case which is more general than Huang's one [33]. Moreover, the authors [7] obtained the same strong convergence conclusion as in Huang's result [33]. In addition, the authors also gave the geometric convergence rate estimate for approximate solutions. Also, various types of iterative algorithms for solving variational inclusions have been further studied and developed; for more details, refer to $[14,22,27,29,32]$ and the references therein.

Let $S$ and $T$ be two nonexpansive mappings. In 2009, Yao, Liou and Marino [19] considered the following hierarchical VIP: find hierarchically a fixed point of $T$, which is a solution to the VIP for monotone mapping $I-S$; namely, find $\tilde{x} \in \operatorname{Fix}(T)$ such that

$$
\langle(I-S) \tilde{x}, p-\tilde{x}\rangle \geq 0, \quad \forall p \in \operatorname{Fix}(T) .
$$


The solution set of the hierarchical VIP (1.7) is denoted by $\Lambda$. It is not hard to check that solving the hierarchical VIP (1.7) is equivalent to the fixed point problem of the composite mapping $P_{\mathrm{Fix}(T)} S$, i.e., find $\tilde{x} \in C$ such that $\tilde{x}=P_{\mathrm{Fix}(T)} S \tilde{x}$. The authors [19] introduced and analyzed the following iterative algorithm for solving the hierarchical VIP (1.7):

$$
\left\{\begin{array}{l}
y_{n}=\beta_{n} S x_{n}+\left(1-\beta_{n}\right) x_{n}, \\
x_{n+1}=\alpha_{n} V x_{n}+\left(1-\alpha_{n}\right) T y_{n}, \quad \forall n \geq 0 .
\end{array}\right.
$$

Theorem YLM (see [19, Theorem 3.2]). Let C be a nonempty closed convex subset of a real Hilbert space $H$. Let $S$ and $T$ be two nonexpansive mappings of $C$ into itself. Let $V: C \rightarrow C$ be a fixed contraction with $\alpha \in(0,1)$. Let $\left\{\alpha_{n}\right\}$ and $\left\{\beta_{n}\right\}$ be two sequences in $(0,1)$. For any given $x_{0} \in C$, let $\left\{x_{n}\right\}$ be the sequence generated by (1.8). Assume that the sequence $\left\{x_{n}\right\}$ is bounded and that

(i) $\sum_{n=0}^{\infty} \alpha_{n}=\infty$;

(ii) $\lim _{n \rightarrow \infty} \frac{1}{\alpha_{n}}\left|\frac{1}{\beta_{n}}-\frac{1}{\beta_{n-1}}\right|=0, \lim _{n \rightarrow \infty} \frac{1}{\beta_{n}}\left|1-\frac{\alpha_{n-1}}{\alpha_{n}}\right|=0$;

(iii) $\lim _{n \rightarrow \infty} \beta_{n}=0, \lim _{n \rightarrow \infty} \frac{\alpha_{n}}{\beta_{n}}=0$ and $\lim _{n \rightarrow \infty} \frac{\beta_{n}^{2}}{\alpha_{n}}=0$;

(iv) $\operatorname{Fix}(T) \cap \operatorname{int} C \neq \varnothing$;

(v) there exists a constant $k>0$ such that $\|x-T x\| \geq k \operatorname{Dist}(x, \operatorname{Fix}(T))$ for each $x \in C$, where $\operatorname{Dist}(x, \operatorname{Fix}(T))=\inf _{y \in \operatorname{Fix}(T)}\|x-y\|$. Then $\left\{x_{n}\right\}$ converges strongly to $\tilde{x}=P_{\Lambda} V \tilde{x}$ which solves the hierarchical VIP

$$
\langle(I-S) \tilde{x}, p-\tilde{x}\rangle \leq 0, \forall p \in \operatorname{Fix}(T)
$$

Very recently, Iiduka $[16,17]$ considered a variational inequality with a variational inequality constraint over the set of fixed points of a nonexpansive mapping. Since this problem has a triple structure in contrast with bilevel programming problems or hierarchical constrained optimization problems or hierarchical fixed point problem, it is refereed as triple hierarchical constrained optimization problem (THCOP). He presented some examples of THCOP and developed iterative algorithms to find the solution of such a problem. The convergence analysis of the proposed algorithms was also studied in [16, 17]. Since the original problem is a variational inequality, in this paper, we call it a triple hierarchical variational inequality (THVI). Subsequently, Zeng, Wong and Yao [22] introduced and considered the following triple hierarchical variational inequality (THVI):

Problem I. Assume that

(i) each $T_{i}: H \rightarrow H$ is a nonexpansive mapping with $\cap_{i=1}^{N} \operatorname{Fix}\left(T_{i}\right) \neq \varnothing$;

(ii) $A_{1}: H \rightarrow H$ is $\alpha$-inverse strongly monotone; 
(iii) $A_{2}: H \rightarrow H$ is $\beta$-strongly monotone and $L$-Lipschitz continuous;

(iv) $\operatorname{VI}\left(\cap_{i=1}^{N} \operatorname{Fix}\left(T_{i}\right), A_{1}\right) \neq \varnothing$.

Then the objective is to

$$
\text { find } \begin{aligned}
x^{*} & \in \operatorname{VI}\left(\operatorname{VI}\left(\cap_{i=1}^{N} \operatorname{Fix}\left(T_{i}\right), A_{1}\right), A_{2}\right) \\
& :=\left\{x^{*} \in \operatorname{VI}\left(\cap_{i=1}^{N} \operatorname{Fix}\left(T_{i}\right), A_{1}\right):\left\langle A_{2} x^{*}, v-x^{*}\right\rangle \geq 0, \forall v \in \operatorname{VI}\left(\cap_{i=1}^{N} \operatorname{Fix}\left(T_{i}\right), A_{1}\right)\right\} .
\end{aligned}
$$

The authors [22] proposed the following algorithm for solving Problem I:

Algorithm ZWY ([22, Algorithm 3.2]). Let $T_{i}: H \rightarrow H(i=1,2, \ldots, N)$ and $A_{i}: H \rightarrow H(i=$ $1,2)$ satisfy assumptions (i)-(iv) in Problem I. The following steps are presented for solving Problem I.

Step 0. Take $\left\{\alpha_{n}\right\}_{n=0}^{\infty} \subset(0,1],\left\{\rho_{n}\right\}_{n=0}^{\infty} \subset(0,2 \alpha], \mu \in\left(0,2 \beta / L^{2}\right)$, choose $x_{0} \in H$ arbitrarily, and let $n:=0$.

Step 1. Given $x_{n} \in H$, compute $x_{n+1} \in H$ as

$$
\left\{\begin{array}{l}
y_{n}=T_{[n+1]}\left(x_{n}-\rho_{n} A_{1} x_{n}\right) \\
x_{n+1}=y_{n}-\mu \alpha_{n} A_{2} y_{n}
\end{array}\right.
$$

where $T_{[k]}:=T_{k \bmod N}$, for integer $k \geq 1$, with the $\bmod$ function taking values in the set $\{1,2, \ldots$, $N\}$, i.e., if $k=j N+q$ for some integers $j \geq 0$ and $0 \leq q<N$, then $T_{[k]}=T_{N}$ if $q=0$ and $T_{[k]}=T_{q}$ if $1 \leq q<N$.

Update $n:=n+1$ and go to Step 1 .

The following convergence analysis was presented in [22] for Algorithm ZWY.

Theorem ZWY ([22, Theorem 3.2]). Let $\mu \in\left(0,2 \beta / L^{2}\right),\left\{\alpha_{n}\right\}_{n=0}^{\infty} \subset(0,1]$, and $\left\{\rho_{n}\right\}_{n=0}^{\infty} \subset(0,2 \alpha]$ such that (i) $\lim _{n \rightarrow \infty} \alpha_{n}=0$, (ii) $\sum_{n=0}^{\infty} \alpha_{n}=\infty$, (iii) $\lim _{n \rightarrow \infty}\left(\alpha_{n}-\alpha_{n+N}\right) / \alpha_{n+N}=0$ or $\sum_{n=0}^{\infty} \mid \alpha_{n+N}$ $-\alpha_{n} \mid<\infty$, (iv) $\lim _{n \rightarrow \infty}\left(\rho_{n}-\rho_{n+N}\right) / \rho_{n+N}=0$ or $\sum_{n=0}^{\infty}\left|\rho_{n+N}-\rho_{n}\right|<\infty$, and (v) $\rho_{n} \leq \alpha_{n}$ for all $n \geq 0$. Assume in addition that

$$
\bigcap_{i=1}^{N} \operatorname{Fix}\left(T_{i}\right)=\operatorname{Fix}\left(T_{1} T_{2} \cdots T_{N}\right)=\operatorname{Fix}\left(T_{N} T_{1} \cdots T_{N-1}\right)=\cdots=\operatorname{Fix}\left(T_{2} T_{3} \cdots T_{N} T_{1}\right) .
$$

Then the sequence $\left\{x_{n}\right\}_{n=0}^{\infty}$ generated by Algorithm ZWY satisfies the following properties:

(a) $\left\{x_{n}\right\}_{n=0}^{\infty}$ is bounded;

(b) $\lim _{n \rightarrow \infty}\left\|x_{n+N}-x_{n}\right\|=0$ and $\lim _{n \rightarrow \infty}\left\|x_{n}-T_{n+N} \cdots T_{n+1} x_{n}\right\|=0$;

(c) $\left\{x_{n}\right\}_{n=0}^{\infty}$ converges strongly to the unique solution of Problem I provided $\left\|x_{n}-y_{n}\right\|=o\left(\rho_{n}\right)$. 
In this paper, we introduce and study the following triple hierarchical variational inequality (THVI) with constraints of GMEP (1.2), SGEP (1.3) and finitely many variational inclusions:

Problem II. Let $N$ be an integer. Assume that

(i) $\left\{T_{n}\right\}_{n=1}^{\infty}$ is a sequence of nonexpansive mappings on $H$, and $A: H \rightarrow H$ and $A_{k}: C \rightarrow$ $H$ are $\zeta$-inverse-strongly monotone and $\zeta_{k}$-inverse-strongly monotone, respectively, for $k=1,2$;

(ii) $\widetilde{A}_{1}: H \rightarrow H$ is $\alpha$-inverse strongly monotone and $\widetilde{A}_{2}: H \rightarrow H$ is $\beta$-strongly monotone and $L$-Lipschitz continuous;

(iii) $\Theta, \Theta_{1}, \Theta_{2}$ are three bifunctions from $C \times C$ to $\mathbf{R}$ satisfying (H1)-(H4), and $\varphi: C \rightarrow \mathbf{R}$ is a lower semicontinuous and convex functional;

(iv) $R_{i}: C \rightarrow 2^{H}$ is a maximal monotone mapping and $B_{i}: C \rightarrow H$ is $\eta_{i}$-inverse strongly monotone for $i=1,2, \ldots, N$;

(v) $\operatorname{VI}\left(\Omega, \widetilde{A}_{1}\right) \neq \varnothing$ where $\Omega:=\cap_{n=1}^{\infty} \operatorname{Fix}\left(T_{n}\right) \cap \operatorname{GMEP}(\Theta, \varphi, A) \cap \cap_{i=1}^{N} \mathrm{I}\left(B_{i}, R_{i}\right) \cap \operatorname{SGEP}(G)$.

Then the objective is to

$$
\text { find } \begin{aligned}
x^{*} & \in \operatorname{VI}\left(\operatorname{VI}\left(\Omega, \widetilde{A}_{1}\right), \widetilde{A}_{2}\right) \\
& :=\left\{x^{*} \in \operatorname{VI}\left(\Omega, \widetilde{A}_{1}\right):\left\langle\widetilde{A}_{2} x^{*}, v-x^{*}\right\rangle \geq 0, \forall v \in \operatorname{VI}\left(\Omega, \widetilde{A}_{1}\right)\right\} .
\end{aligned}
$$

Motivated and inspired by the above facts, we introduce and analyze a relaxed iterative algorithm by combining Korpelevich's extragradient method, hybrid steepest-descent method and Mann's iteration method. It is proven that under mild conditions, the proposed algorithm converges strongly to a common element $x^{*} \in \Omega:=\cap_{n=1}^{\infty} \operatorname{Fix}\left(T_{n}\right) \cap \operatorname{GMEP}(\Theta, \varphi, A) \cap$ $\cap_{i=1}^{N} \mathrm{I}\left(B_{i}, R_{i}\right) \cap \operatorname{SGEP}(G)$ of the solution set of GMEP (1.2), the solution set of SGEP (1.3), the solution set of finitely many variational inclusions and the fixed point set of infinitely many nonexpansive mappings $\left\{T_{n}\right\}_{n=1}^{\infty}$, which is just a unique solution of the THVI (1.9). In addition, we also consider the application of the proposed algorithm to solving a hierarchical variational inequality problem with constraints of GMEP (1.2), SGEP (1.3) and finitely many variational inclusions. That is, under appropriate conditions, it is proven that the proposed algorithm converges strongly to a unique solution $u^{*} \in \Omega$ of the VIP: $\left\langle\widetilde{A}_{2} u^{*}, p-u^{*}\right\rangle \geq 0, \forall p \in \Omega$; equivalently, $P_{\Omega}\left(I-\widetilde{A}_{2}\right) u^{*}=u^{*}$. The results obtained in this paper improve and extend the corresponding results announced by many others.

\section{Preliminaries}

Throughout this paper, we assume that $H$ is a real Hilbert space whose inner product and norm are denoted by $\langle\cdot, \cdot\rangle$ and $\|\cdot\|$, respectively. Let $C$ be a nonempty closed convex subset of $H$. We write $x_{n} \rightarrow x$ to indicate that the sequence $\left\{x_{n}\right\}$ converges weakly to $x$ and $x_{n} \rightarrow x$ to 
indicate that the sequence $\left\{x_{n}\right\}$ converges strongly to $x$. Moreover, we use $\omega_{w}\left(x_{n}\right)$ to denote the weak $\omega$-limit set of the sequence $\left\{x_{n}\right\}$, i.e.,

$$
\omega_{w}\left(x_{n}\right):=\left\{x \in H: x_{n_{i}} \rightarrow x \text { for some subsequence }\left\{x_{n_{i}}\right\} \text { of }\left\{x_{n}\right\}\right\} .
$$

Definition 2.1. A mapping $A: C \rightarrow H$ is called

(i) monotone if

$$
\langle A x-A y, x-y\rangle \geq 0, \quad \forall x, y \in C
$$

(ii) $\eta$-strongly monotone if there exists a constant $\eta>0$ such that

$$
\langle A x-A y, x-y\rangle \geq \eta\|x-y\|^{2}, \quad \forall x, y \in C ;
$$

(iii) $\zeta$-inverse-strongly monotone if there exists a constant $\zeta>0$ such that

$$
\langle A x-A y, x-y\rangle \geq \zeta\|A x-A y\|^{2}, \quad \forall x, y \in C .
$$

It is easy to see that the projection $P_{C}$ is 1-inverse-strongly monotone. Inverse strongly monotone (also referred to as co-coercive) operators have been applied widely in solving practical problems in various fields. It is obvious that if $A$ is $\zeta$-inverse-strongly monotone, then $A$ is monotone and $\frac{1}{\zeta}$-Lipschitz continuous. Moreover, we also have that, for all $u, v \in C$ and $\lambda>0$,

$$
\begin{aligned}
\|(I-\lambda A) u-(I-\lambda A) v\|^{2} & =\|(u-v)-\lambda(A u-A v)\|^{2} \\
& =\|u-v\|^{2}-2 \lambda\langle A u-A v, u-v\rangle+\lambda^{2}\|A u-A v\|^{2} \\
& \leq\|u-v\|^{2}+\lambda(\lambda-2 \zeta)\|A u-A v\|^{2} .
\end{aligned}
$$

So, if $\lambda \leq 2 \zeta$, then $I-\lambda A$ is a nonexpansive mapping from $C$ to $H$.

Definition 2.2. A differentiable function $K: H \rightarrow \mathbf{R}$ is called:

(i) convex, if

$$
K(y)-K(x) \geq\left\langle K^{\prime}(x), y-x\right\rangle, \quad \forall x, y \in H,
$$

where $K^{\prime}(x)$ is the Frechet derivative of $K$ at $x$;

(ii) strongly convex, if there exists a constant $\sigma>0$ such that

$$
K(y)-K(x)-\left\langle K^{\prime}(x), y-x\right\rangle \geq \frac{\sigma}{2}\|x-y\|^{2}, \quad \forall x, y \in H .
$$

It is easy to see that if $K: H \rightarrow \mathbf{R}$ is a differentiable strongly convex function with constant $\sigma>0$ then $K^{\prime}: H \rightarrow H$ is strongly monotone with constant $\sigma>0$. 
The metric (or nearest point) projection from $H$ onto $C$ is the mapping $P_{C}: H \rightarrow C$ which assigns to each point $x \in H$ the unique point $P_{C} x \in C$ satisfying the property

$$
\left\|x-P_{C} x\right\|=\inf _{y \in C}\|x-y\|=: d(x, C)
$$

Some important properties of projections are gathered in the following proposition.

Proposition 2.1. For given $x \in H$ and $z \in C$ :

(i) $z=P_{C} x \Leftrightarrow\langle x-z, y-z\rangle \leq 0, \forall y \in C$;

(ii) $z=P_{C} x \Leftrightarrow\|x-z\|^{2} \leq\|x-y\|^{2}-\|y-z\|^{2}, \forall y \in C$;

(iii) $\left\langle P_{C} x-P_{C} y, x-y\right\rangle \geq\left\|P_{C} x-P_{C} y\right\|^{2}, \forall y \in H$. (This implies that $P_{C}$ is nonexpansive and monotone.)

By using the technique of [21], we can readily obtain the following elementary result.

Proposition 2.2. (see [25, Lemma 1 and Proposition 1]) Let $C$ be a nonempty closed convex subset of a real Hilbert space $H$ and let $\varphi: C \rightarrow \mathbf{R}$ be a lower semicontinuous and convex function. Let $\Theta: C \times C \rightarrow \mathbf{R}$ be a bifunction satisfying the conditions (H1)-(H4). Assume that

(i) $K: H \rightarrow \mathbf{R}$ is strongly convex with constant $\sigma>0$ and the function $x \mapsto\left\langle y-x, K^{\prime}(x)\right\rangle$ is weakly upper semicontinuous for each $y \in H$;

(ii) for each $x \in H$ and $r>0$, there exists a bounded subset $D_{x} \subset C$ and $y_{x} \in C$ such that for any $z \in C \backslash D_{x}$,

$$
\Theta\left(z, y_{x}\right)+\varphi\left(y_{x}\right)-\varphi(z)+\frac{1}{r}\left\langle K^{\prime}(z)-K^{\prime}(x), y_{x}-z\right\rangle<0 .
$$

Then the following hold:

(a) for each $x \in H, S_{r}^{(\Theta, \varphi)}(x) \neq \varnothing$;

(b) $S_{r}^{(\Theta, \varphi)}$ is single-valued;

(c) $S_{r}^{(\Theta, \varphi)}$ is nonexpansive if $K^{\prime}$ is Lipschitz continuous with constant $v>0$ and

$$
\left\langle K^{\prime}\left(x_{1}\right)-K^{\prime}\left(x_{2}\right), u_{1}-u_{2}\right\rangle \leq\left\langle K^{\prime}\left(u_{1}\right)-K^{\prime}\left(u_{2}\right), u_{1}-u_{2}\right\rangle, \quad \forall\left(x_{1}, x_{2}\right) \in H \times H,
$$

where $u_{i}=S_{r}^{(\Theta, \varphi)}\left(x_{i}\right)$ for $i=1,2$;

(d) for all $s, t>0$ and $x \in H$

$$
\left\langle K^{\prime}\left(S_{s}^{(\Theta, \varphi)} x\right)-K^{\prime}\left(S_{t}^{(\Theta, \varphi)} x\right), S_{s}^{(\Theta, \varphi)} x-S_{t}^{(\Theta, \varphi)} x\right\rangle \leq \frac{s-t}{s}\left\langle K^{\prime}\left(S_{s}^{(\Theta, \varphi)} x\right)-K^{\prime}(x), S_{s}^{(\Theta, \varphi)} x-S_{t}^{(\Theta, \varphi)} x\right\rangle
$$

(e) $\operatorname{Fix}\left(S_{r}^{(\Theta, \varphi)}\right)=\operatorname{MEP}(\Theta, \varphi)$; 
(f) $\operatorname{MEP}(\Theta, \varphi)$ is closed and convex.

In particular, whenever $\Theta: C \times C \rightarrow \mathbf{R}$ is a bifunction satisfying the conditions (H1)-(H4) and $K(x)=\frac{1}{2}\|x\|^{2}, \forall x \in H$, then that is, for any $x, y \in H$,

$$
\left\|S_{r}^{(\Theta, \varphi)} x-S_{r}^{(\Theta, \varphi)} y\right\|^{2} \leq\left\langle S_{r}^{(\Theta, \varphi)} x-S_{r}^{(\Theta, \varphi)} y, x-y\right\rangle
$$

$\left(S_{r}^{(\Theta, \varphi)}\right.$ is firmly nonexpansive) and

$$
\left\|S_{s}^{(\Theta, \varphi)} x-S_{t}^{(\Theta, \varphi)} x\right\| \leq \frac{|s-t|}{s}\left\|S_{s}^{(\Theta, \varphi)} x-x\right\|, \quad \forall s, t>0, x \in H
$$

In this case, $S_{r}^{(\Theta, \varphi)}$ is rewritten as $T_{r}^{(\Theta, \varphi)}$. If, in addition, $\varphi \equiv 0$, then $T_{r}^{(\Theta, \varphi)}$ is rewritten as $T_{r}^{\Theta}$ (see [24, Lemma 2.1] for more details).

Remark 2.1. Suppose $K: H \rightarrow \mathbf{R}$ is strongly convex with constant $\sigma>0$ and $K^{\prime}: H \rightarrow H$ is Lipschitz continuous with constant $v>0$. Then $K^{\prime}: H \rightarrow H$ is $\sigma$-strongly monotone and $v$ Lipschitz continuous with positive constants $\sigma, v>0$. Utilizing Proposition 2.2 (d) we obtain that for all $s, t>0$ and $x \in H$

$$
\begin{aligned}
\sigma\left\|S_{s}^{(\Theta, \varphi)} x-S_{t}^{(\Theta, \varphi)} x\right\|^{2} & \leq\left\langle K^{\prime}\left(S_{s}^{(\Theta, \varphi)} x\right)-K^{\prime}\left(S_{t}^{(\Theta, \varphi)} x\right), S_{s}^{(\Theta, \varphi)} x-S_{t}^{(\Theta, \varphi)} x\right\rangle \\
& \leq \frac{s-t}{s}\left\langle K^{\prime}\left(S_{s}^{(\Theta, \varphi)} x\right)-K^{\prime}(x), S_{s}^{(\Theta, \varphi)} x-S_{t}^{(\Theta, \varphi)} x\right\rangle \\
& \leq \frac{|s-t|}{s}\left\|K^{\prime}\left(S_{s}^{(\Theta, \varphi)} x\right)-K^{\prime}(x)\right\|\left\|S_{s}^{(\Theta, \varphi)} x-S_{t}^{(\Theta, \varphi)} x\right\| \\
& \leq \frac{|s-t|}{s} v\left\|S_{s}^{(\Theta, \varphi)} x-x\right\|\left\|S_{s}^{(\Theta, \varphi)} x-S_{t}^{(\Theta, \varphi)} x\right\|,
\end{aligned}
$$

which immediately implies that

$$
\left\|S_{s}^{(\Theta, \varphi)} x-S_{t}^{(\Theta, \varphi)} x\right\| \leq \frac{|s-t|}{s} \cdot \frac{v}{\sigma}\left\|S_{s}^{(\Theta, \varphi)} x-x\right\| .
$$

In 2010, Ceng and Yao [24] transformed the SGEP (1.3) into a fixed point problem in the following way:

Proposition 2.3 (see [24]). Let $\Theta_{1}, \Theta_{2}: C \times C \rightarrow \mathbf{R}$ be two bifunctions satisfying conditions (H1)(H4) and let $A_{k}: C \rightarrow H$ be $\zeta_{k}$-inverse-strongly monotone for $k=1,2$. Let $v_{k} \in\left(0,2 \zeta_{k}\right)$ for $k=1,2$. Then, $\left(x^{*}, y^{*}\right) \in C \times C$ is a solution of SGEP (1.3) if and only if $x^{*}$ is a fixed point of the mapping $G: C \rightarrow C$ defined by $G:=T_{v_{1}}^{\Theta_{1}}\left(I-v_{1} A_{1}\right) T_{v_{2}}^{\Theta_{2}}\left(I-v_{2} A_{2}\right)$, where $y^{*}=T_{v_{2}}^{\Theta_{2}}\left(I-v_{2} A_{2}\right) x^{*}$. Here, we denote the fixed point set of $G$ by $\operatorname{SGEP}(G)$.

We need some facts and tools in a real Hilbert space $H$ which are listed as lemmas below.

Lemma 2.1. Let $X$ be a real inner product space. Then there holds the following inequality

$$
\|x+y\|^{2} \leq\|x\|^{2}+2\langle y, x+y\rangle, \quad \forall x, y \in X .
$$


Lemma 2.2. Let $H$ be a real Hilbert space. Then the following hold:

(a) $\|x-y\|^{2}=\|x\|^{2}-\|y\|^{2}-2\langle x-y, y\rangle$ for all $x, y \in H$;

(b) $\|\lambda x+\mu y\|^{2}=\lambda\|x\|^{2}+\mu\|y\|^{2}-\lambda \mu\|x-y\|^{2}$ for all $x, y \in H$ and $\lambda, \mu \in[0,1]$ with $\lambda+\mu=1$;

(c) If $\left\{x_{n}\right\}$ is a sequence in $H$ such that $x_{n} \rightarrow x$, it follows that

$$
\limsup _{n \rightarrow \infty}\left\|x_{n}-y\right\|^{2}=\limsup _{n \rightarrow \infty}\left\|x_{n}-x\right\|^{2}+\|x-y\|^{2}, \quad \forall y \in H .
$$

Let $\left\{T_{n}\right\}_{n=1}^{\infty}$ be an infinite family of nonexpansive mappings on $H$ and $\left\{\lambda_{n}\right\}_{n=1}^{\infty}$ be a sequence of nonnegative numbers in $[0,1]$. For any $n \geq 1$, define a mapping $W_{n}$ on $H$ as follows:

$$
\left\{\begin{array}{l}
U_{n, n+1}=I \\
U_{n, n}=\lambda_{n} T_{n} U_{n, n+1}+\left(1-\lambda_{n}\right) I \\
U_{n, n-1}=\lambda_{n-1} T_{n-1} U_{n, n}+\left(1-\lambda_{n-1}\right) I \\
\cdots \\
U_{n, k}=\lambda_{k} T_{k} U_{n, k+1}+\left(1-\lambda_{k}\right) I \\
U_{n, k-1}=\lambda_{k-1} T_{k-1} U_{n, k}+\left(1-\lambda_{k-1}\right) I \\
\cdots \\
U_{n, 2}=\lambda_{2} T_{2} U_{n, 3}+\left(1-\lambda_{2}\right) I \\
W_{n}=U_{n, 1}=\lambda_{1} T_{1} U_{n, 2}+\left(1-\lambda_{1}\right) I
\end{array}\right.
$$

Such a mapping $W_{n}$ is called the $W$-mapping generated by $T_{n}, T_{n-1}, \ldots, T_{1}$ and $\lambda_{n}, \lambda_{n-1}, \ldots, \lambda_{1}$.

We have the following crucial lemmas concerning the $W$-mappings defined by (2.2).

Lemma 2.3. (see [3, Lemma 3.2]). Let $\left\{T_{n}\right\}_{n=1}^{\infty}$ be a sequence of nonexpansive mappings on $H$ such that $\cap_{n=1}^{\infty} \operatorname{Fix}\left(T_{n}\right) \neq \varnothing$ and let $\left\{\lambda_{n}\right\}$ be a sequence in $(0, b]$ for some $b \in(0,1)$. Then, for every $x \in H$ and $k \geq 1$ the limit $\lim _{n \rightarrow \infty} U_{n, k} x$ exists, where $U_{n, k}$ is defined by (2.2).

Remark 2.2. (see [31, Remark 3.1]). It can be known from Lemma 2.3 that if $D$ is a nonempty bounded subset of $H$, then for $\epsilon>0$ there exists $n_{0} \geq k$ such that for all $n>n_{0}$

$$
\sup _{x \in D}\left\|U_{n, k} x-U_{k} x\right\| \leq \epsilon .
$$

Remark 2.3. (see [31, Remark 3.2]). Utilizing Lemma 2.3, we define a mapping $W: H \rightarrow H$ as follows:

$$
W x=\lim _{n \rightarrow \infty} W_{n} x=\lim _{n \rightarrow \infty} U_{n, 1} x, \quad \forall x \in H .
$$

Such a $W$ is called the $W$-mapping generated by $T_{1}, T_{2}, \ldots$ and $\lambda_{1}, \lambda_{2}, \ldots$ Since $W_{n}$ is nonexpansive, $W: H \rightarrow H$ is also nonexpansive. Indeed, observe that for each $x, y \in H$

$$
\|W x-W y\|=\lim _{n \rightarrow \infty}\left\|W_{n} x-W_{n} y\right\| \leq\|x-y\| .
$$


If $\left\{x_{n}\right\}$ is a bounded sequence in $H$, then we put $D=\left\{x_{n}: n \geq 1\right\}$. Hence, it is clear from Remark 2.2 that for an arbitrary $\epsilon>0$ there exists $N_{0} \geq 1$ such that for all $n>N_{0}$

$$
\left\|W_{n} x_{n}-W x_{n}\right\|=\left\|U_{n, 1} x_{n}-U_{1} x_{n}\right\| \leq \sup _{x \in D}\left\|U_{n, 1} x-U_{1} x\right\| \leq \epsilon .
$$

This implies that

$$
\lim _{n \rightarrow \infty}\left\|W_{n} x_{n}-W x_{n}\right\|=0 .
$$

Lemma 2.4. (see [3, Lemma 3.3]). Let $\left\{T_{n}\right\}_{n=1}^{\infty}$ be a sequence of nonexpansive mappings on $H$ such that $\cap_{n=1}^{\infty} \operatorname{Fix}\left(T_{n}\right) \neq \varnothing$, and let $\left\{\lambda_{n}\right\}$ be a sequence in $(0, b]$ for some $b \in(0,1)$. Then, $\operatorname{Fix}(W)=\cap_{n=1}^{\infty} \operatorname{Fix}\left(T_{n}\right)$.

Lemma 2.5. (see [4, Demiclosedness principle]). Let $C$ be a nonempty closed convex subset of a real Hilbert space $H$. Let $T$ be a nonexpansive self-mapping on $C$. Then $I-T$ is demiclosed. That is, whenever $\left\{x_{n}\right\}$ is a sequence in $C$ weakly converging to some $x \in C$ and the sequence $\left\{(I-T) x_{n}\right\}$ strongly converges to some $y$, it follows that $(I-T) x=y$. Here $I$ is the identity operator of $H$.

Lemma 2.6. Let $A: C \rightarrow H$ be a monotone mapping. In the context of the variational inequality problem the characterization of the projection (see Proposition 2.1 (i)) implies

$$
u \in \operatorname{VI}(C, A) \Leftrightarrow u=P_{C}(u-\lambda A u), \quad \lambda>0 .
$$

Let $C$ be a nonempty closed convex subset of a real Hilbert space $H$. We introduce some notations. Let $\lambda$ be a number in $(0,1]$ and let $\mu>0$. Associating with a nonexpansive mapping $T: C \rightarrow H$, we define the mapping $T^{\lambda}: C \rightarrow H$ by

$$
T^{\lambda} x:=T x-\lambda \mu F(T x), \quad \forall x \in C,
$$

where $F: H \rightarrow H$ is an operator such that, for some positive constants $\kappa, \eta>0, F$ is $\kappa$-Lipschitzian and $\eta$-strongly monotone on $H$; that is, $F$ satisfies the conditions:

$$
\|F x-F y\| \leq \kappa\|x-y\| \text { and }\langle F x-F y, x-y\rangle \geq \eta\|x-y\|^{2}
$$

for all $x, y \in H$.

Lemma 2.7. (see [1, Lemma 3.1]). $T^{\lambda}$ is a contraction provided $0<\mu<\frac{2 \eta}{\kappa^{2}}$; that is,

$$
\left\|T^{\lambda} x-T^{\lambda} y\right\| \leq(1-\lambda \tau)\|x-y\|, \quad \forall x, y \in C,
$$

where $\tau=1-\sqrt{1-\mu\left(2 \eta-\mu \kappa^{2}\right)} \in(0,1]$. 
Lemma 2.8. [see [1]] Let $\left\{s_{n}\right\}$ be a sequence of nonnegative numbers satisfying the conditions

$$
s_{n+1} \leq\left(1-\alpha_{n}\right) s_{n}+\alpha_{n} \beta_{n}, \quad \forall n \geq 1,
$$

where $\left\{\alpha_{n}\right\}$ and $\left\{\beta_{n}\right\}$ are sequences of real numbers such that

(i) $\left\{\alpha_{n}\right\} \subset[0,1]$ and $\sum_{n=1}^{\infty} \alpha_{n}=\infty$, or equivalently,

$$
\prod_{n=1}^{\infty}\left(1-\alpha_{n}\right):=\lim _{n \rightarrow \infty} \prod_{k=1}^{n}\left(1-\alpha_{k}\right)=0 ;
$$

(ii) $\limsup _{n \rightarrow \infty} \beta_{n} \leq 0$, or $\sum_{n=1}^{\infty}\left|\alpha_{n} \beta_{n}\right|<\infty$.

Then $\lim _{n \rightarrow \infty} s_{n}=0$.

Finally, recall that a set-valued mapping $T: D(T) \subset H \rightarrow 2^{H}$ is called monotone if for all $x, y \in D(T), f \in T x$ and $g \in T y$ imply

$$
\langle f-g, x-y\rangle \geq 0 .
$$

A set-valued mapping $T$ is called maximal monotone if $T$ is monotone and $(I+\lambda T) D(T)=H$ for each $\lambda>0$, where $I$ is the identity mapping of $H$. We denote by $G(T)$ the graph of $T$. It is known that a monotone mapping $T$ is maximal if and only if, for $(x, f) \in H \times H,\langle f-g, x-y\rangle \geq 0$ for every $(y, g) \in G(T)$ implies $f \in T x$. Let $A: C \rightarrow H$ be a monotone, $k$-Lipschitz-continuous mapping and let $N_{C} v$ be the normal cone to $C$ at $v \in C$, i.e.,

$$
N_{C} v=\{u \in H:\langle v-p, u\rangle \geq 0, \forall p \in C\}
$$

Define

$$
\widetilde{T} v= \begin{cases}A v+N_{C} v, & \text { if } v \in C, \\ \varnothing, & \text { if } v \notin C .\end{cases}
$$

Then, $\widetilde{T}$ is maximal monotone (see [5]) such that

$$
0 \in \widetilde{T} v \Longleftrightarrow v \in \operatorname{VI}(C, A) .
$$

Let $R: D(R) \subset H \rightarrow 2^{H}$ be a maximal monotone mapping. Let $\lambda, \mu>0$ be two positive numbers.

Lemma 2.9. [see [6]] There holds the resolvent identity

$$
J_{R, \lambda} x=J_{R, \mu}\left(\frac{\mu}{\lambda} x+\left(1-\frac{\mu}{\lambda}\right) J_{R, \lambda} x\right), \quad \forall x \in H .
$$

Remark 2.4. For $\lambda, \mu>0$, there holds the following relation

$$
\left\|J_{R, \lambda} x-J_{R, \mu} y\right\| \leq\|x-y\|+|\lambda-\mu|\left(\frac{1}{\lambda}\left\|J_{R, \lambda} x-y\right\|+\frac{1}{\mu}\left\|x-J_{R, \mu} y\right\|\right), \quad \forall x, y \in H .
$$


In terms of Huang [33] (see also [7]), there holds the following property for the resolvent operator $J_{R, \lambda}: H \rightarrow \overline{D(R)}$.

Lemma 2.10. $J_{R, \lambda}$ is single-valued and firmly nonexpansive, i.e.,

$$
\left\langle J_{R, \lambda} x-J_{R, \lambda} y, x-y\right\rangle \geq\left\|J_{R, \lambda} x-J_{R, \lambda} y\right\|^{2}, \quad \forall x, y \in H .
$$

Consequently, $J_{R, \lambda}$ is nonexpansive and monotone.

Lemma 2.11 (see [14]). Let $R$ be a maximal monotone mapping with $D(R)=C$. Then for any given $\lambda>0, u \in C$ is a solution of problem (1.6) if and only if $u \in C$ satisfies

$$
u=J_{R, \lambda}(u-\lambda B u) .
$$

Lemma 2.12 (see [7]). Let $R$ be a maximal monotone mapping with $D(R)=C$ and let $B: C \rightarrow$ $H$ be a strongly monotone, continuous and single-valued mapping. Then for each $z \in H$, the equation $z \in(B+\lambda R) x$ has a unique solution $x_{\lambda}$ for $\lambda>0$.

Lemma 2.13 (see [14]). Let $R$ be a maximal monotone mapping with $D(R)=C$ and $B: C \rightarrow H$ be a monotone, continuous and single-valued mapping. Then $(I+\lambda(R+B)) C=H$ for each $\lambda>0$. In this case, $R+B$ is maximal monotone.

\section{Main results}

In this section, we will introduce and analyze a relaxed iterative algorithm for finding a solution of the THVI (1.9) with constraints of several problems: the GMEP (1.2), the SGEP (1.3) and finitely many variational inclusions in a real Hilbert space. This algorithm is based on Korpelevich's extragradient method, hybrid steepest-descent method and Mann's iteration method. We prove the strong convergence of the proposed algorithm to a unique solution of THVI (1.9) under suitable conditions. In addition, we also consider the application of the proposed algorithm to solving a hierarchical VIP with the same constraints.

We are now in a position to state and prove the first main result in this paper.

Theorem 3.1. Let $C$ be a nonempty closed convex subset of a real Hilbert space $H$. Let $N$ be an integer. Let $\Theta, \Theta_{1}, \Theta_{2}$ be three bifunctions from $C \times C$ to $\mathbf{R}$ satisfying $(H 1)-(H 4)$ and $\varphi: C \rightarrow \mathbf{R}$ be a lower semicontinuous and convex functional. Let $R_{i}: C \rightarrow 2^{H}$ be a maximal monotone mapping and $B_{i}: C \rightarrow H$ be $\eta_{i}$-inverse strongly monotone for $i=1,2, \ldots, N$. Let $A: H \rightarrow H$ and $A_{k}: C \rightarrow H$ be $\zeta$-inverse-strongly monotone and $\zeta_{k}$-inverse-strongly monotone, respectively, for $k=1,2$. Let $\left\{T_{n}\right\}_{n=1}^{\infty}$ be a sequence of nonexpansive mappings on $H$ and $\left\{\lambda_{n}\right\}_{n=1}^{\infty}$ be a sequence in $(0, b]$ for some $b \in(0,1)$. Let $\widetilde{A}_{1}: H \rightarrow H$ be $\alpha$-inverse strongly monotone and $\widetilde{A}_{2}: H \rightarrow H$ be $\beta$-strongly monotone and L-Lipschitz continuous. Assume that $\operatorname{VI}\left(\Omega, \widetilde{A}_{1}\right) \neq \varnothing$ where $\Omega:=$ $\cap_{n=1}^{\infty} \operatorname{Fix}\left(T_{n}\right) \cap \operatorname{GMEP}(\Theta, \varphi, A) \cap \operatorname{SGEP}(G) \cap \cap_{i=1}^{N} \mathrm{I}\left(B_{i}, R_{i}\right) \neq \varnothing$ where $G$ is defined as in Proposition 2.3 with $v_{k} \in\left(0,2 \zeta_{k}\right)$ for $k=1,2$. Let $\mu \in\left(0,2 \beta / L^{2}\right),\left\{\alpha_{n}\right\}_{n=1}^{\infty} \subset(0,1],\left\{\rho_{n}\right\}_{n=1}^{\infty} \subset(0,2 \alpha],\left\{\beta_{n}\right\}_{n=1}^{\infty} \subset$ $[a, b] \subset(0,1)$ and $\left\{r_{n}\right\}_{n=1}^{\infty} \subset[c, d] \subset(0,2 \zeta)$. Assume that: 
(i) $K: H \rightarrow \mathbf{R}$ is strongly convex with constant $\sigma>0$ and its derivative $K^{\prime}$ is Lipschitz continuous with constant $v>0$ such that the function $x \mapsto\left\langle y-x, K^{\prime}(x)\right\rangle$ is weakly upper semicontinuous for each $y \in H$;

(ii) for each $x \in H$, there exist a bounded subset $D_{x} \subset C$ and $z_{x} \in C$ such that for any $y \notin D_{x}$,

$$
\Theta\left(y, z_{x}\right)+\varphi\left(z_{x}\right)-\varphi(y)+\frac{1}{r}\left\langle K^{\prime}(y)-K^{\prime}(x), z_{x}-y\right\rangle<0 ;
$$

(iii) $\lim _{n \rightarrow \infty} \alpha_{n}=0, \sum_{n=1}^{\infty} \alpha_{n}=\infty$ and $\lim _{n \rightarrow \infty} \frac{1}{\alpha_{n}}\left|1-\frac{\rho_{n-1}}{\rho_{n}}\right|=0$;

(iv) $\lim _{n \rightarrow \infty} \frac{\rho_{n}}{\alpha_{n}}=0, \lim _{n \rightarrow \infty} \frac{1}{\alpha_{n}}\left|\frac{1}{\rho_{n}}-\frac{1}{\rho_{n-1}}\right|=0$ and $\lim _{n \rightarrow \infty} \frac{1}{\rho_{n}}\left|1-\frac{\alpha_{n-1}}{\alpha_{n}}\right|=0$;

(v) $\lim _{n \rightarrow \infty} \frac{b^{n}}{\alpha_{n} \rho_{n}}=0, \lim _{n \rightarrow \infty} \frac{\left|\beta_{n}-\beta_{n-1}\right|}{\alpha_{n} \rho_{n}}=0$ and $\lim _{n \rightarrow \infty} \frac{\left|r_{n}-r_{n-1}\right|}{\alpha_{n} \rho_{n}}=0$;

(vi) $\left\{\lambda_{i, n}\right\} \subset\left[a_{i}, b_{i}\right] \subset\left(0,2 \eta_{i}\right)$ and $\lim _{n \rightarrow \infty} \frac{\left|\lambda_{i, n}-\lambda_{i, n-1}\right|}{\alpha_{n} \rho_{n}}=0$ for $i=1,2, \ldots, N$.

For arbitrarily given $x_{1} \in H$, let $\left\{x_{n}\right\}$ be a sequence generated by

$$
\left\{\begin{array}{l}
u_{n}=S_{r_{n}}^{(\Theta, \varphi)}\left(I-r_{n} A\right) x_{n}, \\
v_{n}=J_{R_{N}, \lambda_{N, n}}\left(I-\lambda_{N, n} B_{N}\right) J_{R_{N-1}, \lambda_{N-1, n}}\left(I-\lambda_{N-1, n} B_{N-1}\right) \cdots J_{R_{1}, \lambda_{1, n}}\left(I-\lambda_{1, n} B_{1}\right) u_{n}, \\
y_{n}=\beta_{n} G v_{n}+\left(1-\beta_{n}\right) W_{n}\left(v_{n}-\rho_{n} \widetilde{A}_{1} v_{n}\right), \\
x_{n+1}=y_{n}-\mu \alpha_{n} \widetilde{A}_{2} y_{n}, \quad \forall n \geq 1,
\end{array}\right.
$$

where $W_{n}$ be the $W$-mapping defined by (2.2). Then, whenever $S_{r}^{(\Theta, \varphi)}$ is firmly nonexpansive, there hold the following:

(i) $\lim _{n \rightarrow \infty} \frac{\left\|x_{n+1}-x_{n}\right\|}{\rho_{n}}=0$;

(ii) $\omega_{w}\left(x_{n}\right) \subset \Omega$;

(iii) $\omega_{w}\left(x_{n}\right) \subset \operatorname{VI}\left(\Omega, \widetilde{A}_{1}\right)$ provided $\left\|x_{n}-y_{n}\right\|=o\left(\rho_{n}\right)$ additionally.

Proof. Let $\left\{x^{*}\right\}=\operatorname{VI}\left(\operatorname{VI}\left(\Omega, \widetilde{A}_{1}\right), \widetilde{A}_{2}\right)$. Taking into account that $\lim _{n \rightarrow \infty} \frac{\rho_{n}}{\alpha_{n}}=0$, we may assume, without loss of generality, that $\rho_{n} \leq \alpha_{n}$ for all $n \geq 1$. Since $\widetilde{A}_{2}$ is $L$-Lipschitz continuous, we get

$$
\left\|\widetilde{A}_{2} y_{n}-\widetilde{A}_{2} x^{*}\right\| \leq L\left\|y_{n}-x^{*}\right\|, \quad \forall n \geq 1
$$

Put

$$
\Lambda_{n}^{i}=J_{R_{i}, \lambda_{i, n}}\left(I-\lambda_{i, n} B_{i}\right) J_{R_{i-1}, \lambda_{i-1, n}}\left(I-\lambda_{i-1, n} B_{i-1}\right) \cdots J_{R_{1}, \lambda_{1, n}}\left(I-\lambda_{1, n} B_{1}\right)
$$

for all $i \in\{1,2, \ldots, N\}$ and $\Lambda_{n}^{0}=I$, where $I$ is the identity mapping on $H$. Then we have $v_{n}=$ $\Lambda_{n}^{N} u_{n}$

We divide the rest of the proof into several steps.

Step 1. We prove that $\left\{x_{n}\right\}$ is bounded. 
Indeed, take $p \in \Omega$ arbitrarily. Since $p=S_{r_{n}}^{(\Theta, \varphi)}\left(p-r_{n} A p\right), A$ is $\zeta$-inverse strongly monotone and $0 \leq r_{n} \leq 2 \zeta$, utilizing (2.1) and the nonexpansivity of $S_{r_{n}}^{(\Theta, \varphi)}$, we have, for any $n \geq 1$,

$$
\begin{aligned}
\left\|u_{n}-p\right\|^{2} & =\left\|S_{r_{n}}^{(\Theta, \varphi)}\left(I-r_{n} A\right) x_{n}-S_{r_{n}}^{(\Theta, \varphi)}\left(I-r_{n} A\right) p\right\|^{2} \\
& \leq\left\|\left(I-r_{n} A\right) x_{n}-\left(I-r_{n} A\right) p\right\|^{2} \\
& =\left\|\left(x_{n}-p\right)-r_{n}\left(A x_{n}-A p\right)\right\|^{2} \\
& =\left\|x_{n}-p\right\|^{2}-2 r_{n}\left\langle x_{n}-p, A x_{n}-A p\right\rangle+r_{n}^{2}\left\|A x_{n}-A p\right\|^{2} \\
& \leq\left\|x_{n}-p\right\|^{2}-2 r_{n} \zeta\left\|A x_{n}-A p\right\|^{2}+r_{n}^{2}\left\|A x_{n}-A p\right\|^{2} \\
& =\left\|x_{n}-p\right\|^{2}+r_{n}\left(r_{n}-2 \zeta\right)\left\|A x_{n}-A p\right\|^{2} \\
& \leq\left\|x_{n}-p\right\|^{2} .
\end{aligned}
$$

Utilizing (2.1) and Lemma 2.10 we have

$$
\begin{aligned}
\left\|v_{n}-p\right\|= & \left\|J_{R_{N}, \lambda_{N, n}}\left(I-\lambda_{N, n} B_{N}\right) \Lambda_{n}^{N-1} u_{n}-J_{R_{N}, \lambda_{N, n}}\left(I-\lambda_{N, n} B_{N}\right) \Lambda_{n}^{N-1} p\right\| \\
\leq & \left\|\left(I-\lambda_{N, n} B_{N}\right) \Lambda_{n}^{N-1} u_{n}-\left(I-\lambda_{N, n} B_{N}\right) \Lambda_{n}^{N-1} p\right\| \\
\leq & \left\|\Lambda_{n}^{N-1} u_{n}-\Lambda_{n}^{N-1} p\right\| \\
& \cdots \\
\leq & \left\|\Lambda_{n}^{0} u_{n}-\Lambda_{n}^{0} p\right\| \\
= & \left\|u_{n}-p\right\|
\end{aligned}
$$

Combining (3.2) and (3.3), we have

$$
\left\|v_{n}-p\right\| \leq\left\|x_{n}-p\right\|
$$

Since $p=G p=T_{v_{1}}^{\Theta_{1}}\left(I-v_{1} A_{1}\right) T_{v_{2}}^{\Theta_{2}}\left(I-v_{2} A_{2}\right) p, A_{k}$ is $\zeta_{k}$-inverse-strongly monotone for $k=1,2$, and $0 \leq v_{k} \leq 2 \zeta_{k}$ for $k=1,2$, we deduce that, for any $n \geq 1$,

$$
\begin{aligned}
\| & G v_{n}-p \|^{2} \\
= & \left\|T_{v_{1}}^{\Theta_{1}}\left(I-v_{1} A_{1}\right) T_{v_{2}}^{\Theta_{2}}\left(I-v_{2} A_{2}\right) v_{n}-T_{v_{1}}^{\Theta_{1}}\left(I-v_{1} A_{1}\right) T_{v_{2}}^{\Theta_{2}}\left(I-v_{2} A_{2}\right) p\right\|^{2} \\
\leq & \left\|\left(I-v_{1} A_{1}\right) T_{v_{2}}^{\Theta_{2}}\left(I-v_{2} A_{2}\right) v_{n}-\left(I-v_{1} A_{1}\right) T_{v_{2}}^{\Theta_{2}}\left(I-v_{2} A_{2}\right) p\right\|^{2} \\
= & \left\|\left[T_{v_{2}}^{\Theta_{2}}\left(I-v_{2} A_{2}\right) v_{n}-T_{v_{2}}^{\Theta_{2}}\left(I-v_{2} A_{2}\right) p\right]-v_{1}\left[A_{1} T_{v_{2}}^{\Theta_{2}}\left(I-v_{2} A_{2}\right) v_{n}-A_{1} T_{v_{2}}^{\Theta_{2}}\left(I-v_{2} A_{2}\right) p\right]\right\|^{2} \\
\leq & \left\|T_{v_{2}}^{\Theta_{2}}\left(I-v_{2} A_{2}\right) v_{n}-T_{v_{2}}^{\Theta_{2}}\left(I-v_{2} A_{2}\right) p\right\|^{2} \\
& +v_{1}\left(v_{1}-2 \zeta_{1}\right)\left\|A_{1} T_{v_{2}}^{\Theta_{2}}\left(I-v_{2} A_{2}\right) v_{n}-A_{1} T_{v_{2}}^{\Theta_{2}}\left(I-v_{2} A_{2}\right) p\right\|^{2} \\
\leq & \left\|T_{v_{2}}^{\Theta_{2}}\left(I-v_{2} A_{2}\right) v_{n}-T_{v_{2}}^{\Theta_{2}}\left(I-v_{2} A_{2}\right) p\right\|^{2} \\
\leq & \left\|\left(I-v_{2} A_{2}\right) v_{n}-\left(I-v_{2} A_{2}\right) p\right\|^{2} \\
= & \left\|\left(v_{n}-p\right)-v_{2}\left(A_{2} v_{n}-A_{2} p\right)\right\|^{2}
\end{aligned}
$$




$$
\begin{aligned}
& \leq\left\|v_{n}-p\right\|^{2}+v_{2}\left(v_{2}-2 \zeta_{2}\right)\left\|A_{2} v_{n}-A_{2} p\right\|^{2} \\
& \leq\left\|v_{n}-p\right\|^{2} .
\end{aligned}
$$

Since $\widetilde{A}_{1}$ is $\alpha$-inverse strongly monotone and $\left\{\rho_{n}\right\}_{n=1}^{\infty} \subset(0,2 \alpha]$, utilizing (2.1), (3.1), (3.4) and (3.5) we have

$$
\begin{aligned}
\left\|y_{n}-p\right\| & =\left\|\beta_{n}\left(G v_{n}-p\right)+\left(1-\beta_{n}\right)\left[W_{n}\left(v_{n}-\rho_{n} \widetilde{A}_{1} v_{n}\right)-p\right]\right\| \\
& \leq \beta_{n}\left\|G v_{n}-p\right\|+\left(1-\beta_{n}\right)\left\|W_{n}\left(v_{n}-\rho_{n} \widetilde{A}_{1} v_{n}\right)-p\right\| \\
& \leq \beta_{n}\left\|v_{n}-p\right\|+\left(1-\beta_{n}\right)\left\|\left(v_{n}-\rho_{n} \widetilde{A}_{1} v_{n}\right)-p\right\| \\
& =\beta_{n}\left\|v_{n}-p\right\|+\left(1-\beta_{n}\right)\left\|\left(I-\rho_{n} \widetilde{A}_{1}\right) v_{n}-\left(I-\rho_{n} \widetilde{A}_{1}\right) p-\rho_{n} \widetilde{A}_{1} p\right\| \\
& \leq \beta_{n}\left\|v_{n}-p\right\|+\left(1-\beta_{n}\right)\left(\left\|\left(I-\rho_{n} \widetilde{A}_{1}\right) v_{n}-\left(I-\rho_{n} \widetilde{A}_{1}\right) p\right\|+\rho_{n}\left\|\widetilde{A}_{1} p\right\|\right) \\
& \leq \beta_{n}\left\|v_{n}-p\right\|+\left(1-\beta_{n}\right)\left(\left\|v_{n}-p\right\|+\rho_{n}\left\|\widetilde{A}_{1} p\right\|\right) \\
& \leq\left\|v_{n}-p\right\|+\rho_{n}\left\|\widetilde{A}_{1} p\right\| \\
& \leq\left\|x_{n}-p\right\|+\rho_{n}\left\|\widetilde{A}_{1} p\right\| .
\end{aligned}
$$

Utilizing Lemma 2.7, we obtain from (3.1) and $\rho_{n} \leq \alpha_{n}$ that

$$
\begin{aligned}
\left\|x_{n+1}-p\right\| & =\left\|y_{n}-\mu \alpha_{n} \widetilde{A}_{2} y_{n}-p\right\| \\
& \leq\left\|\left(I-\mu \alpha_{n} \widetilde{A}_{2}\right) y_{n}-\left(I-\mu \alpha_{n} \widetilde{A}_{2}\right) p\right\|+\left\|\left(I-\mu \alpha_{n} \widetilde{A}_{2}\right) p-p\right\| \\
& \leq\left(1-\alpha_{n} \tau\right)\left\|y_{n}-p\right\|+\mu \alpha_{n}\left\|\widetilde{A}_{2} p\right\| \\
& \leq\left(1-\alpha_{n} \tau\right)\left[\left\|x_{n}-p\right\|+\rho_{n}\left\|\widetilde{A}_{1} p\right\|\right]+\alpha_{n} \mu\left\|\widetilde{A}_{2} p\right\| \\
& \leq\left(1-\alpha_{n} \tau\right)\left\|x_{n}-p\right\|+\rho_{n}\left\|\widetilde{A}_{1} p\right\|+\alpha_{n} \mu\left\|\widetilde{A}_{2} p\right\| \\
& \leq\left(1-\alpha_{n} \tau\right)\left\|x_{n}-p\right\|+\alpha_{n}\left(\left\|\widetilde{A}_{1} p\right\|+\mu\left\|\widetilde{A}_{2} p\right\|\right) \\
& =\left(1-\alpha_{n} \tau\right)\left\|x_{n}-p\right\|+\alpha_{n} \tau \cdot \frac{\left\|\widetilde{A}_{1} p\right\|+\mu\left\|\widetilde{A}_{2} p\right\|}{\tau} \\
& \leq \max \left\{\left\|x_{n}-p\right\|, \frac{\left\|\widetilde{A}_{1} p\right\|+\mu\left\|\widetilde{A}_{2} p\right\|}{\tau}\right\},
\end{aligned}
$$

where $\tau:=1-\sqrt{1-\mu\left(2 \beta-\mu L^{2}\right)}$. By induction, we find that

$$
\left\|x_{n}-p\right\| \leq \max \left\{\left\|x_{1}-p\right\|, \frac{\left\|\widetilde{A}_{1} p\right\|+\mu\left\|\widetilde{A}_{2} p\right\|}{\tau}\right\}, \quad \forall n \geq 1 .
$$

Thus, $\left\{x_{n}\right\}_{n=1}^{\infty}$ is bounded and so are the sequences $\left\{u_{n}\right\}_{n=1}^{\infty},\left\{v_{n}\right\}_{n=1}^{\infty}$ and $\left\{y_{n}\right\}_{n=1}^{\infty}$.

Step 2. We prove that $\lim _{n \rightarrow \infty} \frac{\left\|x_{n+1}-x_{n}\right\|}{\rho_{n}}=0$.

Indeed, put $\tilde{v}_{n}=v_{n}-\rho_{n} \widetilde{A}_{1} v_{n}$ for all $n \geq 1$. Utilizing (2.1) and (2.4), we obtain that

$$
\left\|v_{n+1}-v_{n}\right\|=\left\|\Lambda_{n+1}^{N} u_{n+1}-\Lambda_{n}^{N} u_{n}\right\|
$$




$$
\begin{aligned}
= & \left\|J_{R_{N}, \lambda_{N, n+1}}\left(I-\lambda_{N, n+1} B_{N}\right) \Lambda_{n+1}^{N-1} u_{n+1}-J_{R_{N}, \lambda_{N, n}}\left(I-\lambda_{N, n} B_{N}\right) \Lambda_{n}^{N-1} u_{n}\right\| \\
\leq & \left\|J_{R_{N}, \lambda_{N, n+1}}\left(I-\lambda_{N, n+1} B_{N}\right) \Lambda_{n+1}^{N-1} u_{n+1}-J_{R_{N}, \lambda_{N, n+1}}\left(I-\lambda_{N, n} B_{N}\right) \Lambda_{n+1}^{N-1} u_{n+1}\right\| \\
& +\left\|J_{R_{N}, \lambda_{N, n+1}}\left(I-\lambda_{N, n} B_{N}\right) \Lambda_{n+1}^{N-1} u_{n+1}-J_{R_{N}, \lambda_{N, n}}\left(I-\lambda_{N, n} B_{N}\right) \Lambda_{n}^{N-1} u_{n}\right\| \\
\leq & \left\|\left(I-\lambda_{N, n+1} B_{N}\right) \Lambda_{n+1}^{N-1} u_{n+1}-\left(I-\lambda_{N, n} B_{N}\right) \Lambda_{n+1}^{N-1} u_{n+1}\right\| \\
& +\left\|\left(I-\lambda_{N, n} B_{N}\right) \Lambda_{n+1}^{N-1} u_{n+1}-\left(I-\lambda_{N, n} B_{N}\right) \Lambda_{n}^{N-1} u_{n}\right\|+\left|\lambda_{N, n+1}-\lambda_{N, n}\right| \\
& \times\left(\frac{1}{\lambda_{N, n+1}}\left\|J_{R_{N}, \lambda_{N, n+1}}\left(I-\lambda_{N, n} B_{N}\right) \Lambda_{n+1}^{N-1} u_{n+1}-\left(I-\lambda_{N, n} B_{N}\right) \Lambda_{n}^{N-1} u_{n}\right\|\right. \\
& \left.+\frac{1}{\lambda_{N, n}}\left\|\left(I-\lambda_{N, n} B_{N}\right) \Lambda_{n+1}^{N-1} u_{n+1}-J_{R_{N}, \lambda_{N, n}}\left(I-\lambda_{N, n} B_{N}\right) \Lambda_{n}^{N-1} u_{n}\right\|\right) \\
\leq & \left|\lambda_{N, n+1}-\lambda_{N, n}\right|\left(\left\|B_{N} \Lambda_{n+1}^{N-1} u_{n+1}\right\|+\widetilde{M}\right)+\left\|\Lambda_{n+1}^{N-1} u_{n+1}-\Lambda_{n}^{N-1} u_{n}\right\| \\
\leq & \left|\lambda_{N, n+1}-\lambda_{N, n}\right|\left(\left\|B_{N} \Lambda_{n+1}^{N-1} u_{n+1}\right\|+\widetilde{M}\right) \\
& +\left|\lambda_{N-1, n+1}-\lambda_{N-1, n}\right|\left(\left\|B_{N-1} \Lambda_{n+1}^{N-2} u_{n+1}\right\|+\widetilde{M}\right)+\left\|\Lambda_{n+1}^{N-2} u_{n+1}-\Lambda_{n}^{N-2} u_{n}\right\| \\
& \ldots \\
\leq & \left|\lambda_{N, n+1}-\lambda_{N, n}\right|\left(\left\|B_{N} \Lambda_{n+1}^{N-1} u_{n+1}\right\|+\widetilde{M}\right) \\
& +\left|\lambda_{N-1, n+1}-\lambda_{N-1, n}\right|\left(\left\|B_{N-1} \Lambda_{n+1}^{N-2} u_{n+1}\right\|+\widetilde{M}\right) \\
& +\cdots+\left|\lambda_{1, n+1}-\lambda_{1, n}\right|\left(\left\|B_{1} \Lambda_{n+1}^{0} u_{n+1}\right\|+\widetilde{M}\right)+\left\|\Lambda_{n+1}^{0} u_{n+1}-\Lambda_{n}^{0} u_{n}\right\| \\
\leq & \widetilde{M} \sum_{i=1}^{N}\left|\lambda_{i, n+1}-\lambda_{i, n}\right|+\left\|u_{n+1}-u_{n}\right\|, \\
&
\end{aligned}
$$

where

$$
\begin{aligned}
& \sup _{n \geq 1,1 \leq i \leq N}\left\{\frac{1}{\lambda_{i, n+1}}\left\|J_{R_{i}, \lambda_{i, n+1}}\left(I-\lambda_{i, n} B_{i}\right) \Lambda_{n+1}^{i-1} u_{n+1}-\left(I-\lambda_{i, n} B_{N}\right) \Lambda_{n}^{i-1} u_{n}\right\|\right. \\
& \left.+\frac{1}{\lambda_{i, n}}\left\|\left(I-\lambda_{i, n} B_{i}\right) \Lambda_{n+1}^{i-1} u_{n+1}-J_{R_{i}, \lambda_{i, n}}\left(I-\lambda_{i, n} B_{i}\right) \Lambda_{n}^{i-1} u_{n}\right\|\right\} \leq \widetilde{M},
\end{aligned}
$$

for some $\widetilde{M}>0$ and $\sup _{n \geq 1}\left\{\sum_{i=1}^{N}\left\|B_{i} \Lambda_{n+1}^{i-1} u_{n+1}\right\|+\widetilde{M}\right\} \leq \widetilde{M}_{0}$ for some $\widetilde{M}_{0}>0$. Hence, it follows from (2.1) and $\left\{\rho_{n}\right\}_{n=1}^{\infty} \subset(0,2 \alpha]$ that

$$
\begin{aligned}
& \left\|\widetilde{v}_{n+1}-\tilde{v}_{n}\right\| \\
& =\left\|\left(v_{n+1}-\rho_{n+1} \widetilde{A}_{1} v_{n+1}\right)-\left(v_{n}-\rho_{n} \widetilde{A}_{1} v_{n}\right)\right\| \\
& \leq\left\|\left(v_{n+1}-\rho_{n+1} \widetilde{A}_{1} v_{n+1}\right)-\left(v_{n}-\rho_{n+1} \widetilde{A}_{1} v_{n}\right)\right\|+\left\|\left(v_{n}-\rho_{n+1} \widetilde{A}_{1} v_{n}\right)-\left(v_{n}-\rho_{n} \widetilde{A}_{1} v_{n}\right)\right\| \\
& \leq\left\|v_{n+1}-v_{n}\right\|+\left|\rho_{n+1}-\rho_{n}\right|\left\|\widetilde{A}_{1} v_{n}\right\| \\
& \leq \widetilde{M}_{0} \sum_{i=1}^{N}\left|\lambda_{i, n+1}-\lambda_{i, n}\right|+\left\|u_{n+1}-u_{n}\right\|+\left|\rho_{n+1}-\rho_{n}\right|\left\|\widetilde{A}_{1} v_{n}\right\| .
\end{aligned}
$$

Also, utilizing (2.1), $\left\{r_{n}\right\}_{n=1}^{\infty} \subset[c, d] \subset(0,2 \zeta)$ and Remark 2.1, we deduce that

$$
\left\|u_{n+1}-u_{n}\right\|
$$




$$
\begin{aligned}
& =\left\|S_{r_{n+1}}^{(\Theta, \varphi)}\left(I-r_{n+1} A\right) x_{n+1}-S_{r_{n}}^{(\Theta, \varphi)}\left(I-r_{n} A\right) x_{n}\right\| \\
& =\| S_{r_{n+1}}^{(\Theta, \varphi)}\left(I-r_{n+1} A\right) x_{n+1}-S_{r_{n+1}}^{(\Theta, \varphi)}\left(I-r_{n} A\right) x_{n} \\
& +S_{r_{n+1}}^{(\Theta, \varphi)}\left(I-r_{n} A\right) x_{n}-S_{r_{n}}^{(\Theta, \varphi)}\left(I-r_{n} A\right) x_{n} \| \\
& \leq\left\|S_{r_{n+1}}^{(\Theta, \varphi)}\left(I-r_{n+1} A\right) x_{n+1}-S_{r_{n+1}}^{(\Theta, \varphi)}\left(I-r_{n} A\right) x_{n}\right\| \\
& +\left\|S_{r_{n+1}}^{(\Theta, \varphi)}\left(I-r_{n} A\right) x_{n}-S_{r_{n}}^{(\Theta, \varphi)}\left(I-r_{n} A\right) x_{n}\right\| \\
& \leq\left\|\left(I-r_{n+1} A\right) x_{n+1}-\left(I-r_{n} A\right) x_{n}\right\|+\left\|S_{r_{n+1}}^{(\Theta, \varphi)}\left(I-r_{n} A\right) x_{n}-S_{r_{n}}^{(\Theta, \varphi)}\left(I-r_{n} A\right) x_{n}\right\| \\
& \leq\left\|x_{n+1}-x_{n}\right\|+\left|r_{n+1}-r_{n}\right|\left\|A x_{n}\right\|+\left\|S_{r_{n+1}}^{(\Theta, \varphi)}\left(I-r_{n} A\right) x_{n}-S_{r_{n}}^{(\Theta, \varphi)}\left(I-r_{n} A\right) x_{n}\right\| \\
& \leq\left\|x_{n+1}-x_{n}\right\|+\left|r_{n+1}-r_{n}\right|\left\|A x_{n}\right\|+\frac{\left|r_{n+1}-r_{n}\right|}{r_{n+1}} \cdot \frac{v}{\sigma}\left\|S_{r_{n+1}}^{(\Theta, \varphi)}\left(I-r_{n} A\right) x_{n}-\left(I-r_{n} A\right) x_{n}\right\| \\
& \leq\left\|x_{n+1}-x_{n}\right\|+\left|r_{n+1}-r_{n}\right|\left(\left\|A x_{n}\right\|+\frac{v}{c \sigma}\left\|S_{r_{n+1}}^{(\Theta, \varphi)}\left(I-r_{n} A\right) x_{n}-\left(I-r_{n} A\right) x_{n}\right\|\right) \\
& \leq\left\|x_{n+1}-x_{n}\right\|+\left|r_{n+1}-r_{n}\right| \widetilde{M}_{1} \text {, }
\end{aligned}
$$

where $\sup _{n \geq 1}\left\{\left\|A x_{n}\right\|+\frac{v}{c \sigma}\left\|S_{r_{n+1}}^{(\Theta, \varphi)}\left(I-r_{n} A\right) x_{n}-\left(I-r_{n} A\right) x_{n}\right\|\right\} \leq \widetilde{M}_{1}$ for some $\widetilde{M}_{1}>0$. In the meantime, from (2.2), since $W_{n}, T_{n}$ and $U_{n, i}$ are all nonexpansive, we have

$$
\begin{aligned}
\left\|W_{n+1} \tilde{v}_{n}-W_{n} \tilde{v}_{n}\right\|= & \left\|\lambda_{1} T_{1} U_{n+1,2} \tilde{v}_{n}-\lambda_{1} T_{1} U_{n, 2} \tilde{v}_{n}\right\| \\
\leq & \lambda_{1}\left\|U_{n+1,2} \tilde{v}_{n}-U_{n, 2} \tilde{v}_{n}\right\| \\
= & \lambda_{1}\left\|\lambda_{2} T_{2} U_{n+1,3} \tilde{v}_{n}-\lambda_{2} T_{2} U_{n, 3} \tilde{v}_{n}\right\| \\
\leq & \lambda_{1} \lambda_{2}\left\|U_{n+1,3} \tilde{v}_{n}-U_{n, 3} \tilde{v}_{n}\right\| \\
& \cdots \\
\leq & \lambda_{1} \lambda_{2} \cdots \lambda_{n}\left\|U_{n+1, n+1} \tilde{v}_{n}-U_{n, n+1} \tilde{v}_{n}\right\| \\
\leq & \widetilde{M}_{2} \prod_{i=1}^{n} \lambda_{i},
\end{aligned}
$$

where $\widetilde{M}_{2}$ is a constant such that $\left\|U_{n+1, n+1} \tilde{v}_{n}\right\|+\left\|U_{n, n+1} \tilde{v}_{n}\right\| \leq \widetilde{M}_{2}$ for each $n \geq 1$. Now, simple calculation shows that

$y_{n+1}-y_{n}=\beta_{n}\left(G v_{n+1}-G v_{n}\right)+\left(\beta_{n+1}-\beta_{n}\right)\left(G v_{n+1}-W_{n+1} \widetilde{v}_{n+1}\right)+\left(1-\beta_{n}\right)\left(W_{n+1} \widetilde{v}_{n+1}-W_{n} \tilde{v}_{n}\right)$.

So, utilizing (2.1), (3.6)-(3.9), from $\left\{\lambda_{n}\right\} \subset(0, b] \subset(0,1),\left\{\alpha_{n}\right\} \subset(0,1],\left\{\rho_{n}\right\} \subset(0,2 \alpha]$ and $\mu \in$ $\left(0, \frac{2 \beta}{L^{2}}\right)$ we deduce that

$$
\begin{aligned}
& \left\|y_{n+1}-y_{n}\right\| \\
& \leq \beta_{n}\left\|G v_{n+1}-G v_{n}\right\|+\left|\beta_{n+1}-\beta_{n}\right|\left\|G v_{n+1}-W_{n+1} \widetilde{v}_{n+1}\right\|+\left(1-\beta_{n}\right)\left\|W_{n+1} \widetilde{v}_{n+1}-W_{n} \tilde{v}_{n}\right\| \\
& \leq \beta_{n}\left\|v_{n+1}-v_{n}\right\|+\left|\beta_{n+1}-\beta_{n}\right|\left\|G v_{n+1}-W_{n+1} \widetilde{v}_{n+1}\right\|+\left(1-\beta_{n}\right)\left[\left\|W_{n+1} \widetilde{v}_{n+1}-W_{n+1} \tilde{v}_{n}\right\|\right. \\
& \left.\quad+\left\|W_{n+1} \tilde{v}_{n}-W_{n} \tilde{v}_{n}\right\|\right]
\end{aligned}
$$




$$
\begin{aligned}
\leq & \beta_{n}\left\|v_{n+1}-v_{n}\right\|+\left|\beta_{n+1}-\beta_{n}\right|\left\|G v_{n+1}-W_{n+1} \widetilde{v}_{n+1}\right\|+\left(1-\beta_{n}\right)\left[\left\|\widetilde{v}_{n+1}-\widetilde{v}_{n}\right\|+\widetilde{M}_{2} \prod_{i=1}^{n} \lambda_{i}\right] \\
\leq & \beta_{n}\left[\widetilde{M}_{0} \sum_{i=1}^{N}\left|\lambda_{i, n+1}-\lambda_{i, n}\right|+\left\|u_{n+1}-u_{n}\right\|\right]+\left|\beta_{n+1}-\beta_{n}\right|\left\|G v_{n+1}-W_{n+1} \widetilde{v}_{n+1}\right\| \\
& +\left(1-\beta_{n}\right)\left[\widetilde{M}_{0} \sum_{i=1}^{N}\left|\lambda_{i, n+1}-\lambda_{i, n}\right|+\left\|u_{n+1}-u_{n}\right\|+\left|\rho_{n+1}-\rho_{n}\right|\left\|\widetilde{A}_{1} v_{n}\right\|+\widetilde{M}_{2} \prod_{i=1}^{n} \lambda_{i}\right] \\
\leq & \widetilde{M}_{0} \sum_{i=1}^{N}\left|\lambda_{i, n+1}-\lambda_{i, n}\right|+\left\|u_{n+1}-u_{n}\right\|+\left|\beta_{n+1}-\beta_{n}\right|\left\|G v_{n+1}-W_{n+1} \widetilde{v}_{n+1}\right\| \\
& +\left|\rho_{n+1}-\rho_{n}\right|\left\|\widetilde{A}_{1} v_{n}\right\|+\widetilde{M}_{2} \prod_{i=1}^{n} \lambda_{i} \\
\leq & \widetilde{M}_{0} \sum_{i=1}^{N}\left|\lambda_{i, n+1}-\lambda_{i, n}\right|+\left\|x_{n+1}-x_{n}\right\|+\left|r_{n+1}-r_{n}\right| \widetilde{M}_{1} \\
& +\left|\beta_{n+1}-\beta_{n}\right|\left\|G v_{n+1}-W_{n+1} \widetilde{v}_{n+1}\right\|+\left|\rho_{n+1}-\rho_{n}\right|\left\|\widetilde{A}_{1} v_{n}\right\|+\widetilde{M}_{2} b^{n},
\end{aligned}
$$

and by Lemma 2.7,

$$
\begin{aligned}
\left\|x_{n+2}-x_{n+1}\right\| & \\
= & \left\|\left(I-\mu \alpha_{n+1} \widetilde{A}_{2}\right) y_{n+1}-\left(I-\mu \alpha_{n} \widetilde{A}_{2}\right) y_{n}\right\| \\
\leq & \left\|\left(I-\mu \alpha_{n+1} \widetilde{A}_{2}\right) y_{n+1}-\left(I-\mu \alpha_{n+1} \widetilde{A}_{2}\right) y_{n}\right\|+\left\|\left(I-\mu \alpha_{n+1} \widetilde{A}_{2}\right) y_{n}-\left(I-\mu \alpha_{n} \widetilde{A}_{2}\right) y_{n}\right\| \\
\leq & \left(1-\alpha_{n+1} \tau\right)\left\|y_{n+1}-y_{n}\right\|+\left|\alpha_{n+1}-\alpha_{n}\right| \mu\left\|\widetilde{A}_{2} y_{n}\right\| \\
\leq & \left(1-\alpha_{n+1} \tau\right)\left[\widetilde{M}_{0} \sum_{i=1}^{N}\left|\lambda_{i, n+1}-\lambda_{i, n}\right|+\left\|x_{n+1}-x_{n}\right\|+\left|r_{n+1}-r_{n}\right| \widetilde{M}_{1}\right. \\
& \left.+\left|\beta_{n+1}-\beta_{n}\right|\left\|G v_{n+1}-W_{n+1} \widetilde{v}_{n+1}\right\|+\left|\rho_{n+1}-\rho_{n}\right|\left\|\widetilde{A}_{1} v_{n}\right\|+\widetilde{M}_{2} b^{n}\right]+\left|\alpha_{n+1}-\alpha_{n}\right| \mu\left\|\widetilde{A}_{2} y_{n}\right\| \\
\leq & \left(1-\alpha_{n+1} \tau\right)\left\|x_{n+1}-x_{n}\right\|+\widetilde{M}_{0} \sum_{i=1}^{N}\left|\lambda_{i, n+1}-\lambda_{i, n}\right|+\left|r_{n+1}-r_{n}\right| \widetilde{M}_{1} \\
& +\left|\beta_{n+1}-\beta_{n}\right|\left\|G v_{n+1}-W_{n+1} \widetilde{v}_{n+1}\right\|+\left|\rho_{n+1}-\rho_{n}\right|\left\|\widetilde{A}_{1} v_{n}\right\|+\widetilde{M}_{2} b^{n}+\left|\alpha_{n+1}-\alpha_{n}\right| \mu\left\|\widetilde{A}_{2} y_{n}\right\| \\
\leq & \left(1-\alpha_{n+1} \tau\right)\left\|x_{n+1}-x_{n}\right\|+\widetilde{M}_{3} \sum_{i=1}^{N}\left|\lambda_{i, n+1}-\lambda_{i, n}\right|+\widetilde{M}_{3}\left|r_{n+1}-r_{n}\right| \\
& +\widetilde{M}_{3}\left|\beta_{n+1}-\beta_{n}\right|+\widetilde{M}_{3}\left|\rho_{n+1}-\rho_{n}\right|+\widetilde{M}_{3} b^{n}+\widetilde{M}_{3}\left|\alpha_{n+1}-\alpha_{n}\right| \\
= & \left(1-\alpha_{n+1} \tau\right)\left\|x_{n+1}-x_{n}\right\|+\widetilde{M}_{3}\left(\sum_{i=1}^{N}\left|\lambda_{i, n+1}-\lambda_{i, n}\right|+\left|r_{n+1}-r_{n}\right|\right. \\
& \left.+\left|\beta_{n+1}-\beta_{n}\right|+\left|\rho_{n+1}-\rho_{n}\right|+\left|\alpha_{n+1}-\alpha_{n}\right|+b^{n}\right),
\end{aligned}
$$

where $\sup _{n \geq 1}\left\{\widetilde{M}_{0}+\widetilde{M}_{1}+\widetilde{M}_{2}+\left\|G v_{n}-W_{n} \widetilde{v}_{n}\right\|+\left\|\widetilde{A}_{1} v_{n}\right\|+\mu\left\|\widetilde{A}_{2} y_{n}\right\|\right\} \leq \widetilde{M}_{3}$ for some $\widetilde{M}_{3}>0$. Consequently,

$\frac{\left\|x_{n+1}-x_{n}\right\|}{\rho_{n}}$ 


$$
\begin{aligned}
\leq & \left(1-\alpha_{n} \tau\right) \frac{\left\|x_{n}-x_{n-1}\right\|}{\rho_{n}}+\widetilde{M}_{3}\left(\sum_{i=1}^{N} \frac{\left|\lambda_{i, n}-\lambda_{i, n-1}\right|}{\rho_{n}}+\frac{\left|r_{n}-r_{n-1}\right|}{\rho_{n}}\right. \\
& \left.+\frac{\left|\beta_{n}-\beta_{n-1}\right|}{\rho_{n}}+\frac{\left|\rho_{n}-\rho_{n-1}\right|}{\rho_{n}}+\frac{\left|\alpha_{n}-\alpha_{n-1}\right|}{\rho_{n}}+\frac{b^{n-1}}{\rho_{n}}\right) \\
= & \left(1-\tau \alpha_{n}\right) \frac{\left\|x_{n}-x_{n-1}\right\|}{\rho_{n-1}}+\left(1-\tau \alpha_{n}\right)\left\|x_{n}-x_{n-1}\right\|\left(\frac{1}{\rho_{n}}-\frac{1}{\rho_{n-1}}\right) \\
& +\widetilde{M}_{3}\left(\sum_{i=1}^{N} \frac{\left|\lambda_{i, n}-\lambda_{i, n-1}\right|}{\rho_{n}}+\frac{\left|r_{n}-r_{n-1}\right|}{\rho_{n}}+\frac{\left|\beta_{n}-\beta_{n-1}\right|}{\rho_{n}}+\frac{\left|\rho_{n}-\rho_{n-1}\right|}{\rho_{n}}+\frac{\left|\alpha_{n}-\alpha_{n-1}\right|}{\rho_{n}}+\frac{b^{n-1}}{\rho_{n}}\right) \\
\leq & \left(1-\tau \alpha_{n}\right) \frac{\left\|x_{n}-x_{n-1}\right\|}{\rho_{n-1}}+\tau \alpha_{n} \cdot \frac{\widetilde{M}_{4}}{\tau}\left\{\frac{1}{\alpha_{n}}\left|\frac{1}{\rho_{n}}-\frac{1}{\rho_{n-1}}\right|\right. \\
& \left.+\sum_{i=1}^{N} \frac{\left|\lambda_{i, n}-\lambda_{i, n-1}\right|}{\alpha_{n} \rho_{n}}+\frac{\left|r_{n}-r_{n-1}\right|}{\alpha_{n} \rho_{n}}+\frac{\left|\beta_{n}-\beta_{n-1}\right|}{\alpha_{n} \rho_{n}}+\frac{1}{\alpha_{n}}\left|1-\frac{\rho_{n-1}}{\rho_{n}}\right|+\frac{1}{\rho_{n}}\left|1-\frac{\alpha_{n-1}}{\alpha_{n}}\right|+\frac{b^{n-1}}{\alpha_{n} \rho_{n}}\right\},(3.1
\end{aligned}
$$

where $\sup _{n \geq 1}\left\{\left\|x_{n+1}-x_{n}\right\|+\widetilde{M}_{3}\right\} \leq \widetilde{M}_{4}$ for some $\widetilde{M}_{4}>0$. From (iii)-(vi) it follows that $\sum_{n=1}^{\infty} \tau \alpha_{n}=$ $\infty$ and

$$
\begin{aligned}
\lim _{n \rightarrow \infty} & \frac{\widetilde{M}_{4}}{\tau}\left\{\frac{1}{\alpha_{n}}\left|\frac{1}{\rho_{n}}-\frac{1}{\rho_{n-1}}\right|+\sum_{i=1}^{N} \frac{\left|\lambda_{i, n}-\lambda_{i, n-1}\right|}{\alpha_{n} \rho_{n}}+\frac{\left|r_{n}-r_{n-1}\right|}{\alpha_{n} \rho_{n}}\right. \\
& \left.+\frac{\left|\beta_{n}-\beta_{n-1}\right|}{\alpha_{n} \rho_{n}}+\frac{1}{\alpha_{n}}\left|1-\frac{\rho_{n-1}}{\rho_{n}}\right|+\frac{1}{\rho_{n}}\left|1-\frac{\alpha_{n-1}}{\alpha_{n}}\right|+\frac{b^{n-1}}{\alpha_{n} \rho_{n}}\right\}=0 .
\end{aligned}
$$

Thus, applying Lemma 2.8 to (3.10), we immediately conclude that

$$
\lim _{n \rightarrow \infty} \frac{\left\|x_{n+1}-x_{n}\right\|}{\rho_{n}}=0 .
$$

So, from (iv) it follows that

$$
\lim _{n \rightarrow \infty}\left\|x_{n+1}-x_{n}\right\|=0
$$

Step 3. We prove that $\lim _{n \rightarrow \infty}\left\|x_{n}-u_{n}\right\|=0, \lim _{n \rightarrow \infty}\left\|x_{n}-v_{n}\right\|=0, \lim _{n \rightarrow \infty}\left\|v_{n}-G v_{n}\right\|=0$ and $\lim _{n \rightarrow \infty}\left\|\tilde{v}_{n}-W \tilde{v}_{n}\right\|=0$ where $\tilde{v}_{n}=v_{n}-\rho_{n} \widetilde{A}_{1} v_{n}$.

Indeed, utilizing Lemmas 2.1 and 2.2 (b), from (3.1) and (3.4) we get

$$
\begin{aligned}
& \left\|x_{n+1}-p\right\|^{2} \\
& \quad=\left\|\left(I-\mu \alpha_{n} \widetilde{A}_{2}\right) y_{n}-p\right\|^{2} \\
& \quad=\left\|\left(I-\mu \alpha_{n} \widetilde{A}_{2}\right) y_{n}-\left(I-\mu \alpha_{n} \widetilde{A}_{2}\right) p+\left(I-\mu \alpha_{n} \widetilde{A}_{2}\right) p-p\right\|^{2} \\
& \quad \leq\left\|\left(I-\mu \alpha_{n} \widetilde{A}_{2}\right) y_{n}-\left(I-\mu \alpha_{n} \widetilde{A}_{2}\right) p\right\|^{2}-2 \mu \alpha_{n}\left\langle\widetilde{A}_{2} p, x_{n+1}-p\right\rangle \\
& \quad \leq\left(1-\alpha_{n} \tau\right)\left\|y_{n}-p\right\|^{2}-2 \mu \alpha_{n}\left\langle\widetilde{A}_{2} p, x_{n+1}-p\right\rangle \\
& \quad \leq\left\|y_{n}-p\right\|^{2}-2 \mu \alpha_{n}\left\langle\widetilde{A}_{2} p, x_{n+1}-p\right\rangle \\
& \quad=\left\|\beta_{n}\left(G v_{n}-p\right)+\left(1-\beta_{n}\right)\left(W_{n} \tilde{v}_{n}-p\right)\right\|^{2}-2 \mu \alpha_{n}\left\langle\widetilde{A}_{2} p, x_{n+1}-p\right\rangle
\end{aligned}
$$




$$
\begin{aligned}
= & \beta_{n}\left\|G v_{n}-p\right\|^{2}+\left(1-\beta_{n}\right)\left\|W_{n} \tilde{v}_{n}-p\right\|^{2}-\beta_{n}\left(1-\beta_{n}\right)\left\|G v_{n}-W_{n} \tilde{v}_{n}\right\|^{2} \\
& -2 \mu \alpha_{n}\left\langle\widetilde{A}_{2} p, x_{n+1}-p\right\rangle \\
\leq & \beta_{n}\left\|G v_{n}-p\right\|^{2}+\left(1-\beta_{n}\right)\left\|\tilde{v}_{n}-p\right\|^{2}-\beta_{n}\left(1-\beta_{n}\right)\left\|G v_{n}-W_{n} \tilde{v}_{n}\right\|^{2} \\
& -2 \mu \alpha_{n}\left\langle\widetilde{A}_{2} p, x_{n+1}-p\right\rangle \\
= & \beta_{n}\left\|G v_{n}-p\right\|^{2}+\left(1-\beta_{n}\right)\left\|v_{n}-p-\rho_{n} \widetilde{A}_{1} v_{n}\right\|^{2}-\beta_{n}\left(1-\beta_{n}\right)\left\|G v_{n}-W_{n} \tilde{v}_{n}\right\|^{2} \\
& -2 \mu \alpha_{n}\left\langle\widetilde{A}_{2} p, x_{n+1}-p\right\rangle \\
\leq & \beta_{n}\left\|G v_{n}-p\right\|^{2}+\left(1-\beta_{n}\right)\left(\left\|v_{n}-p\right\|^{2}-2 \rho_{n}\left\langle\widetilde{A}_{1} v_{n}, \tilde{v}_{n}-p\right\rangle\right) \\
& -\beta_{n}\left(1-\beta_{n}\right)\left\|G v_{n}-W_{n} \tilde{v}_{n}\right\|^{2}-2 \mu \alpha_{n}\left\langle\widetilde{A}_{2} p, x_{n+1}-p\right\rangle \\
\leq & \left\|v_{n}-p\right\|^{2}-2 \rho_{n}\left(1-\beta_{n}\right)\left\langle\widetilde{A}_{1} v_{n}, \tilde{v}_{n}-p\right\rangle \\
& -\beta_{n}\left(1-\beta_{n}\right)\left\|G v_{n}-W_{n} \tilde{v}_{n}\right\|^{2}-2 \mu \alpha_{n}\left\langle\widetilde{A}_{2} p, x_{n+1}-p\right\rangle \\
\leq & \left\|x_{n}-p\right\|^{2}-2 \rho_{n}\left(1-\beta_{n}\right)\left\langle\widetilde{A}_{1} v_{n}, \tilde{v}_{n}-p\right\rangle \\
& -\beta_{n}\left(1-\beta_{n}\right)\left\|G v_{n}-W_{n} \tilde{v}_{n}\right\|^{2}-2 \mu \alpha_{n}\left\langle\widetilde{A}_{2} p, x_{n+1}-p\right\rangle,
\end{aligned}
$$

which implies that

$$
\begin{aligned}
\beta_{n}\left(1-\beta_{n}\right)\left\|G v_{n}-W_{n} \tilde{v}_{n}\right\|^{2} \leq & \left\|x_{n}-p\right\|^{2}-\left\|x_{n+1}-p\right\|^{2}-2 \rho_{n}\left(1-\beta_{n}\right)\left\langle\widetilde{A}_{1} v_{n}, \tilde{v}_{n}-p\right\rangle \\
& -2 \mu \alpha_{n}\left\langle\widetilde{A}_{2} p, x_{n+1}-p\right\rangle \\
\leq & \left\|x_{n}-x_{n+1}\right\|\left(\left\|x_{n}-p\right\|+\left\|x_{n+1}-p\right\|\right)+2 \rho_{n}\left\|\widetilde{A}_{1} v_{n}\right\|\left\|\tilde{v}_{n}-p\right\| \\
& +2 \mu \alpha_{n}\left\|\widetilde{A}_{2} p\right\|\left\|x_{n+1}-p\right\| .
\end{aligned}
$$

Since $\alpha_{n} \rightarrow 0, \rho_{n} \rightarrow 0,\left\|x_{n+1}-x_{n}\right\| \rightarrow 0$ and $\left\{x_{n}\right\},\left\{v_{n}\right\},\left\{\tilde{v}_{n}\right\}$ are bounded sequences, it follows from $\left\{\beta_{n}\right\}_{n=1}^{\infty} \subset[a, b] \subset(0,1)$ that

$$
\lim _{n \rightarrow \infty}\left\|G v_{n}-W_{n} \tilde{v}_{n}\right\|=0 .
$$

On the other hand, for $p \in \Omega$, we find that

$$
\begin{aligned}
\left\|u_{n}-p\right\|^{2} & =\left\|S_{r_{n}}^{(\Theta, \varphi)}\left(I-r_{n} A\right) x_{n}-S_{r_{n}}^{(\Theta, \varphi)}\left(I-r_{n} A\right) p\right\|^{2} \\
& \leq\left\|\left(I-r_{n} A\right) x_{n}-\left(I-r_{n} A\right) p\right\|^{2} \\
& =\left\|x_{n}-p-r_{n}\left(A x_{n}-A p\right)\right\|^{2} \\
& \leq\left\|x_{n}-p\right\|^{2}+r_{n}\left(r_{n}-2 \zeta\right)\left\|A x_{n}-A p\right\|^{2} .
\end{aligned}
$$

which together with (3.3) and (3.11), implies that

$$
\begin{aligned}
& \left\|x_{n+1}-p\right\|^{2} \\
& \leq\left\|v_{n}-p\right\|^{2}-2 \rho_{n}\left(1-\beta_{n}\right)\left\langle\widetilde{A}_{1} v_{n}, \tilde{v}_{n}-p\right\rangle \\
& \quad-\beta_{n}\left(1-\beta_{n}\right)\left\|G v_{n}-W_{n} \tilde{v}_{n}\right\|^{2}-2 \mu \alpha_{n}\left\langle\widetilde{A}_{2} p, x_{n+1}-p\right\rangle \\
& \leq\left\|u_{n}-p\right\|^{2}+2 \rho_{n}\left\|\widetilde{A}_{1} v_{n}\right\|\left\|\tilde{v}_{n}-p\right\|+2 \mu \alpha_{n}\left\|\widetilde{A}_{2} p\right\|\left\|x_{n+1}-p\right\| \\
& \leq\left\|x_{n}-p\right\|^{2}+r_{n}\left(r_{n}-2 \zeta\right)\left\|A x_{n}-A p\right\|^{2}+2 \rho_{n}\left\|\widetilde{A}_{1} v_{n}\right\|\left\|\tilde{v}_{n}-p\right\|+2 \mu \alpha_{n}\left\|\widetilde{A}_{2} p\right\|\left\|x_{n+1}-p\right\|,
\end{aligned}
$$


which immediately yields

$$
\begin{aligned}
& r_{n}\left(2 \zeta-r_{n}\right)\left\|A x_{n}-A p\right\|^{2} \\
& \leq\left\|x_{n}-p\right\|^{2}-\left\|x_{n+1}-p\right\|^{2}+2 \rho_{n}\left\|\widetilde{A}_{1} v_{n}\right\|\left\|\tilde{v}_{n}-p\right\|+2 \mu \alpha_{n}\left\|\widetilde{A}_{2} p\right\|\left\|x_{n+1}-p\right\| \\
& \leq\left\|x_{n}-x_{n+1}\right\|\left(\left\|x_{n}-p\right\|+\left\|x_{n+1}-p\right\|\right)+2 \rho_{n}\left\|\widetilde{A}_{1} v_{n}\right\|\left\|\tilde{v}_{n}-p\right\|+2 \mu \alpha_{n}\left\|\widetilde{A}_{2} p\right\|\left\|x_{n+1}-p\right\| .
\end{aligned}
$$

Since $\alpha_{n} \rightarrow 0, \rho_{n} \rightarrow 0,\left\|x_{n+1}-x_{n}\right\| \rightarrow 0$ and $\left\{x_{n}\right\},\left\{v_{n}\right\},\left\{\tilde{v}_{n}\right\}$ are bounded sequences, it follows from $\left\{r_{n}\right\}_{n=1}^{\infty} \subset[c, d] \subset(0,2 \zeta)$ that

$$
\lim _{n \rightarrow \infty}\left\|A x_{n}-A p\right\|=0
$$

Furthermore, from the firm nonexpansivity of $S_{r_{n}}^{(\Theta, \varphi)}$, we have

$$
\begin{aligned}
& \left\|u_{n}-p\right\|^{2} \\
& =\left\|S_{r_{n}}^{(\Theta, \varphi)}\left(I-r_{n} A\right) x_{n}-S_{r_{n}}^{(\Theta, \varphi)}\left(I-r_{n} A\right) p\right\|^{2} \\
& \leq\left\langle\left(I-r_{n} A\right) x_{n}-\left(I-r_{n} A\right) p, u_{n}-p\right\rangle \\
& =\frac{1}{2}\left[\left\|\left(I-r_{n} A\right) x_{n}-\left(I-r_{n} A\right) p\right\|^{2}+\left\|u_{n}-p\right\|^{2}-\left\|\left(I-r_{n} A\right) x_{n}-\left(I-r_{n} A\right) p-\left(u_{n}-p\right)\right\|^{2}\right] \\
& \leq \frac{1}{2}\left[\left\|x_{n}-p\right\|^{2}+\left\|u_{n}-p\right\|^{2}-\left\|x_{n}-u_{n}-r_{n}\left(A x_{n}-A p\right)\right\|^{2}\right] \\
& =\frac{1}{2}\left[\left\|x_{n}-p\right\|^{2}+\left\|u_{n}-p\right\|^{2}-\left\|x_{n}-u_{n}\right\|^{2}+2 r_{n}\left\langle A x_{n}-A p, x_{n}-u_{n}\right\rangle-r_{n}^{2}\left\|A x_{n}-A p\right\|^{2}\right],
\end{aligned}
$$

which leads to

$$
\left\|u_{n}-p\right\|^{2} \leq\left\|x_{n}-p\right\|^{2}-\left\|x_{n}-u_{n}\right\|^{2}+2 r_{n}\left\|A x_{n}-A p\right\|\left\|x_{n}-u_{n}\right\| .
$$

From (3.3), (3.11) and (3.14), we have

$$
\begin{aligned}
\left\|x_{n+1}-p\right\|^{2} \leq & \left\|v_{n}-p\right\|^{2}-2 \rho_{n}\left(1-\beta_{n}\right)\left\langle\widetilde{A}_{1} v_{n}, \tilde{v}_{n}-p\right\rangle \\
& -\beta_{n}\left(1-\beta_{n}\right)\left\|G v_{n}-W_{n} \tilde{v}_{n}\right\|^{2}-2 \mu \alpha_{n}\left\langle\widetilde{A}_{2} p, x_{n+1}-p\right\rangle \\
\leq & \left\|u_{n}-p\right\|^{2}+2 \rho_{n}\left\|\widetilde{A}_{1} v_{n}\right\|\left\|\tilde{v}_{n}-p\right\|+2 \mu \alpha_{n}\left\|\widetilde{A}_{2} p\right\|\left\|x_{n+1}-p\right\| \\
\leq & \left\|x_{n}-p\right\|^{2}-\left\|x_{n}-u_{n}\right\|^{2}+2 r_{n}\left\|A x_{n}-A p\right\|\left\|x_{n}-u_{n}\right\|+2 \rho_{n}\left\|\widetilde{A}_{1} v_{n}\right\|\left\|\tilde{v}_{n}-p\right\| \\
& +2 \mu \alpha_{n}\left\|\widetilde{A}_{2} p\right\|\left\|x_{n+1}-p\right\|,
\end{aligned}
$$

which hence yields

$$
\begin{aligned}
& \left\|x_{n}-u_{n}\right\|^{2} \\
& \leq\left\|x_{n}-p\right\|^{2}-\left\|x_{n+1}-p\right\|^{2}+2 r_{n}\left\|A x_{n}-A p\right\|\left\|x_{n}-u_{n}\right\|+2 \rho_{n}\left\|\widetilde{A}_{1} v_{n}\right\|\left\|\tilde{v}_{n}-p\right\| \\
& \quad+2 \mu \alpha_{n}\left\|\widetilde{A}_{2} p\right\|\left\|x_{n+1}-p\right\| \\
& \leq\left\|x_{n}-x_{n+1}\right\|\left(\left\|x_{n}-p\right\|+\left\|x_{n+1}-p\right\|\right)+2 r_{n}\left\|A x_{n}-A p\right\|\left\|x_{n}-u_{n}\right\|+2 \rho_{n}\left\|\widetilde{A}_{1} v_{n}\right\|\left\|\tilde{v}_{n}-p\right\| \\
& \quad+2 \mu \alpha_{n}\left\|\widetilde{A}_{2} p\right\|\left\|x_{n+1}-p\right\| .
\end{aligned}
$$

Since $\alpha_{n} \rightarrow 0, \rho_{n} \rightarrow 0,\left\|x_{n+1}-x_{n}\right\| \rightarrow 0$ and $\left\{x_{n}\right\},\left\{u_{n}\right\},\left\{v_{n}\right\},\left\{\tilde{v}_{n}\right\}$ are bounded sequences, it follows from (3.13) and $\left\{r_{n}\right\}_{n=1}^{\infty} \subset[c, d] \subset(0,2 \zeta)$ that

$$
\lim _{n \rightarrow \infty}\left\|x_{n}-u_{n}\right\|=0
$$


Next we show that $\lim _{n \rightarrow \infty}\left\|A_{i} \Lambda_{n}^{i} u_{n}-A_{i} p\right\|=0, i=1,2, \ldots, N$. Observe that

$$
\begin{aligned}
\left\|\Lambda_{n}^{i} u_{n}-p\right\|^{2} & =\left\|J_{R_{i}, \lambda_{i, n}}\left(I-\lambda_{i, n} B_{i}\right) \Lambda_{n}^{i-1} u_{n}-J_{R_{i}, \lambda_{i, n}}\left(I-\lambda_{i, n} B_{i}\right) p\right\|^{2} \\
& \leq\left\|\left(I-\lambda_{i, n} B_{i}\right) \Lambda_{n}^{i-1} u_{n}-\left(I-\lambda_{i, n} B_{i}\right) p\right\|^{2} \\
& \leq\left\|\Lambda_{n}^{i-1} u_{n}-p\right\|^{2}+\lambda_{i, n}\left(\lambda_{i, n}-2 \eta_{i}\right)\left\|B_{i} \Lambda_{n}^{i-1} u_{n}-B_{i} p\right\|^{2} \\
& \leq\left\|u_{n}-p\right\|^{2}+\lambda_{i, n}\left(\lambda_{i, n}-2 \eta_{i}\right)\left\|B_{i} \Lambda_{n}^{i-1} u_{n}-B_{i} p\right\|^{2} \\
& \leq\left\|x_{n}-p\right\|^{2}+\lambda_{i, n}\left(\lambda_{i, n}-2 \eta_{i}\right)\left\|B_{i} \Lambda_{n}^{i-1} u_{n}-B_{i} p\right\|^{2} .
\end{aligned}
$$

Combining (3.11) and (3.16), we get

$$
\begin{aligned}
\left\|x_{n+1}-p\right\|^{2} \leq & \left\|v_{n}-p\right\|^{2}-2 \rho_{n}\left(1-\beta_{n}\right)\left\langle\widetilde{A}_{1} v_{n}, \tilde{v}_{n}-p\right\rangle \\
& -\beta_{n}\left(1-\beta_{n}\right)\left\|G v_{n}-W_{n} \tilde{v}_{n}\right\|^{2}-2 \mu \alpha_{n}\left\langle\widetilde{A}_{2} p, x_{n+1}-p\right\rangle \\
\leq & \left\|\Lambda_{n}^{i} u_{n}-p\right\|^{2}+2 \rho_{n}\left\|\widetilde{A}_{1} v_{n}\right\|\left\|\tilde{v}_{n}-p\right\|+2 \mu \alpha_{n}\left\|\widetilde{A}_{2} p\right\|\left\|x_{n+1}-p\right\| \\
\leq & \left\|x_{n}-p\right\|^{2}+\lambda_{i, n}\left(\lambda_{i, n}-2 \eta_{i}\right)\left\|B_{i} \Lambda_{n}^{i-1} u_{n}-B_{i} p\right\|^{2} \\
& +2 \rho_{n}\left\|\widetilde{A}_{1} v_{n}\right\|\left\|\tilde{v}_{n}-p\right\|+2 \mu \alpha_{n}\left\|\widetilde{A}_{2} p\right\|\left\|x_{n+1}-p\right\|,
\end{aligned}
$$

which hence yields

$$
\begin{aligned}
& \lambda_{i, n}\left(2 \eta_{i}-\lambda_{i, n}\right)\left\|B_{i} \Lambda_{n}^{i-1} u_{n}-B_{i} p\right\|^{2} \\
& \leq\left\|x_{n}-p\right\|^{2}-\left\|x_{n+1}-p\right\|^{2}+2 \rho_{n}\left\|\widetilde{A}_{1} v_{n}\right\|\left\|\tilde{v}_{n}-p\right\|+2 \mu \alpha_{n}\left\|\widetilde{A}_{2} p\right\|\left\|x_{n+1}-p\right\| \\
& \leq\left\|x_{n}-x_{n+1}\right\|\left(\left\|x_{n}-p\right\|+\left\|x_{n+1}-p\right\|\right)+2 \rho_{n}\left\|\widetilde{A}_{1} v_{n}\right\|\left\|\tilde{v}_{n}-p\right\|+2 \mu \alpha_{n}\left\|\widetilde{A}_{2} p\right\|\left\|x_{n+1}-p\right\| .
\end{aligned}
$$

Since $\alpha_{n} \rightarrow 0, \rho_{n} \rightarrow 0,\left\|x_{n+1}-x_{n}\right\| \rightarrow 0$ and $\left\{x_{n}\right\},\left\{v_{n}\right\},\left\{\tilde{v}_{n}\right\}$ are bounded sequences, it follows from $\left\{\lambda_{i, n}\right\} \subset\left[a_{i}, b_{i}\right] \subset\left(0,2 \eta_{i}\right), \forall i \in\{1,2, \ldots, N\}$ that

$$
\lim _{n \rightarrow \infty}\left\|B_{i} \Lambda_{n}^{i-1} u_{n}-B_{i} p\right\|=0, \quad \forall i \in\{1,2, \ldots, N\} .
$$

By Lemma 2.2 (a) and Lemma 2.10, we obtain

$$
\begin{aligned}
\| & \Lambda_{n}^{i} u_{n}-p \|^{2} \\
= & \left\|J_{R_{i}, \lambda_{i, n}}\left(I-\lambda_{i, n} B_{i}\right) \Lambda_{n}^{i-1} u_{n}-J_{R_{i}, \lambda_{i, n}}\left(I-\lambda_{i, n} B_{i}\right) p\right\|^{2} \\
\leq & \left\langle\left(I-\lambda_{i, n} B_{i}\right) \Lambda_{n}^{i-1} u_{n}-\left(I-\lambda_{i, n} B_{i}\right) p, \Lambda_{n}^{i} u_{n}-p\right\rangle \\
= & \frac{1}{2}\left(\left\|\left(I-\lambda_{i, n} B_{i}\right) \Lambda_{n}^{i-1} u_{n}-\left(I-\lambda_{i, n} B_{i}\right) p\right\|^{2}+\left\|\Lambda_{n}^{i} u_{n}-p\right\|^{2}\right. \\
& \left.-\left\|\left(I-\lambda_{i, n} B_{i}\right) \Lambda_{n}^{i-1} u_{n}-\left(I-\lambda_{i, n} B_{i}\right) p-\left(\Lambda_{n}^{i} u_{n}-p\right)\right\|^{2}\right) \\
\leq & \frac{1}{2}\left(\left\|\Lambda_{n}^{i-1} u_{n}-p\right\|^{2}+\left\|\Lambda_{n}^{i} u_{n}-p\right\|^{2}-\left\|\Lambda_{n}^{i-1} u_{n}-\Lambda_{n}^{i} u_{n}-\lambda_{i, n}\left(B_{i} \Lambda_{n}^{i-1} u_{n}-B_{i} p\right)\right\|^{2}\right) \\
\leq & \frac{1}{2}\left(\left\|u_{n}-p\right\|^{2}+\left\|\Lambda_{n}^{i} u_{n}-p\right\|^{2}-\left\|\Lambda_{n}^{i-1} u_{n}-\Lambda_{n}^{i} u_{n}-\lambda_{i, n}\left(B_{i} \Lambda_{n}^{i-1} u_{n}-B_{i} p\right)\right\|^{2}\right)
\end{aligned}
$$




$$
\leq \frac{1}{2}\left(\left\|x_{n}-p\right\|^{2}+\left\|\Lambda_{n}^{i} u_{n}-p\right\|^{2}-\left\|\Lambda_{n}^{i-1} u_{n}-\Lambda_{n}^{i} u_{n}-\lambda_{i, n}\left(B_{i} \Lambda_{n}^{i-1} u_{n}-B_{i} p\right)\right\|^{2}\right),
$$

which implies

$$
\begin{aligned}
\left\|\Lambda_{n}^{i} u_{n}-p\right\|^{2} \leq & \left\|x_{n}-p\right\|^{2}-\left\|\Lambda_{n}^{i-1} u_{n}-\Lambda_{n}^{i} u_{n}-\lambda_{i, n}\left(B_{i} \Lambda_{n}^{i-1} u_{n}-B_{i} p\right)\right\|^{2} \\
= & \left\|x_{n}-p\right\|^{2}-\left\|\Lambda_{n}^{i-1} u_{n}-\Lambda_{n}^{i} u_{n}\right\|^{2}-\lambda_{i, n}^{2}\left\|B_{i} \Lambda_{n}^{i-1} u_{n}-B_{i} p\right\|^{2} \\
& +2 \lambda_{i, n}\left\langle\Lambda_{n}^{i-1} u_{n}-\Lambda_{n}^{i} u_{n}, B_{i} \Lambda_{n}^{i-1} u_{n}-B_{i} p\right\rangle \\
\leq & \left\|x_{n}-p\right\|^{2}-\left\|\Lambda_{n}^{i-1} u_{n}-\Lambda_{n}^{i} u_{n}\right\|^{2}+2 \lambda_{i, n}\left\|\Lambda_{n}^{i-1} u_{n}-\Lambda_{n}^{i} u_{n}\right\|\left\|B_{i} \Lambda_{n}^{i-1} u_{n}-B_{i} p\right\| .
\end{aligned}
$$

Combining (3.11) and (3.18) we conclude that

$$
\begin{aligned}
\left\|x_{n+1}-p\right\|^{2} \leq & \left\|v_{n}-p\right\|^{2}-2 \rho_{n}\left(1-\beta_{n}\right)\left\langle\widetilde{A}_{1} v_{n}, \tilde{v}_{n}-p\right\rangle \\
& -\beta_{n}\left(1-\beta_{n}\right)\left\|G v_{n}-W_{n} \tilde{v}_{n}\right\|^{2}-2 \mu \alpha_{n}\left\langle\widetilde{A}_{2} p, x_{n+1}-p\right\rangle \\
\leq & \left\|\Lambda_{n}^{i} u_{n}-p\right\|^{2}+2 \rho_{n}\left\|\widetilde{A}_{1} v_{n}\right\|\left\|\tilde{v}_{n}-p\right\|+2 \mu \alpha_{n}\left\|\widetilde{A}_{2} p\right\|\left\|x_{n+1}-p\right\| \\
\leq & \left\|x_{n}-p\right\|^{2}-\left\|\Lambda_{n}^{i-1} u_{n}-\Lambda_{n}^{i} u_{n}\right\|^{2}+2 \lambda_{i, n}\left\|\Lambda_{n}^{i-1} u_{n}-\Lambda_{n}^{i} u_{n}\right\|\left\|B_{i} \Lambda_{n}^{i-1} u_{n}-B_{i} p\right\| \\
& +2 \rho_{n}\left\|\widetilde{A}_{1} v_{n}\right\|\left\|\tilde{v}_{n}-p\right\|+2 \mu \alpha_{n}\left\|\widetilde{A}_{2} p\right\|\left\|x_{n+1}-p\right\|,
\end{aligned}
$$

which implies

$$
\begin{aligned}
& \left\|\Lambda_{n}^{i-1} u_{n}-\Lambda_{n}^{i} u_{n}\right\|^{2} \\
& \leq\left\|x_{n}-p\right\|^{2}-\left\|x_{n+1}-p\right\|^{2}+2 \lambda_{i, n}\left\|\Lambda_{n}^{i-1} u_{n}-\Lambda_{n}^{i} u_{n}\right\|\left\|B_{i} \Lambda_{n}^{i-1} u_{n}-B_{i} p\right\| \\
& \quad+2 \rho_{n}\left\|\widetilde{A}_{1} v_{n}\right\|\left\|\tilde{v}_{n}-p\right\|+2 \mu \alpha_{n}\left\|\widetilde{A}_{2} p\right\|\left\|x_{n+1}-p\right\| \\
& \leq\left\|x_{n}-x_{n+1}\right\|\left(\left\|x_{n}-p\right\|+\left\|x_{n+1}-p\right\|\right)+2 \lambda_{i, n}\left\|\Lambda_{n}^{i-1} u_{n}-\Lambda_{n}^{i} u_{n}\right\|\left\|B_{i} \Lambda_{n}^{i-1} u_{n}-B_{i} p\right\| \\
& \quad+2 \rho_{n}\left\|\widetilde{A}_{1} v_{n}\right\|\left\|\tilde{v}_{n}-p\right\|+2 \mu \alpha_{n}\left\|\widetilde{A}_{2} p\right\|\left\|x_{n+1}-p\right\| .
\end{aligned}
$$

Since $\alpha_{n} \rightarrow 0, \rho_{n} \rightarrow 0,\left\|x_{n+1}-x_{n}\right\| \rightarrow 0$ and $\left\{x_{n}\right\},\left\{u_{n}\right\},\left\{v_{n}\right\},\left\{\tilde{v}_{n}\right\}$ are bounded sequences, it follows from (3.17) and $\left\{\lambda_{i, n}\right\} \subset\left[a_{i}, b_{i}\right] \subset\left(0,2 \eta_{i}\right), \forall i \in\{1,2, \ldots, N\}$ that

$$
\lim _{n \rightarrow \infty}\left\|\Lambda_{n}^{i-1} u_{n}-\Lambda_{n}^{i} u_{n}\right\|=0, \quad \forall i \in\{1,2, \ldots, N\}
$$

Hence from (3.19) we get

$$
\begin{aligned}
\left\|u_{n}-v_{n}\right\| & =\left\|\Lambda_{n}^{0} u_{n}-\Lambda_{n}^{N} u_{n}\right\| \\
& \leq\left\|\Lambda_{n}^{0} u_{n}-\Lambda_{n}^{1} u_{n}\right\|+\left\|\Lambda_{n}^{1} u_{n}-\Lambda_{n}^{2} u_{n}\right\|+\cdots+\left\|\Lambda_{n}^{N-1} u_{n}-\Lambda_{n}^{N} u_{n}\right\| \\
& \rightarrow 0 \quad \text { as } n \rightarrow \infty
\end{aligned}
$$

Thus, from (3.15) and (3.20) we obtain

$$
\begin{aligned}
\left\|x_{n}-v_{n}\right\| & \leq\left\|x_{n}-u_{n}\right\|+\left\|u_{n}-v_{n}\right\| \\
& \rightarrow 0 \quad \text { as } n \rightarrow \infty
\end{aligned}
$$


On the other hand, for simplicity, we write $\tilde{p}=T_{v_{2}}^{\Theta_{2}}\left(I-v_{2} A_{2}\right) p, z_{n}=T_{v_{2}}^{\Theta_{2}}\left(I-v_{2} A_{2}\right) v_{n}$ and $\tilde{z}_{n}=G v_{n}=T_{v_{1}}^{\Theta_{l}}\left(I-v_{1} A_{1}\right) z_{n}$ for all $n \geq 1$. Then

$$
p=G p=T_{v_{1}}^{\Theta_{1}}\left(I-v_{1} A_{1}\right) \tilde{p}=T_{v_{1}}^{\Theta_{1}}\left(I-v_{1} A_{1}\right) T_{v_{2}}^{\Theta_{2}}\left(I-v_{2} A_{2}\right) p
$$

We now show that $\lim _{n \rightarrow \infty}\left\|G v_{n}-v_{n}\right\|=0$, i.e., $\lim _{n \rightarrow \infty}\left\|\tilde{z}_{n}-v_{n}\right\|=0$. As a matter of fact, for $p \in \Omega$, it follows from (3.4), (3.5) and (3.11) that

$$
\begin{aligned}
\left\|x_{n+1}-p\right\|^{2} \leq & \beta_{n}\left\|G v_{n}-p\right\|^{2}+\left(1-\beta_{n}\right)\left(\left\|v_{n}-p\right\|^{2}-2 \rho_{n}\left\langle\widetilde{A}_{1} v_{n}, \tilde{v}_{n}-p\right\rangle\right) \\
& -\beta_{n}\left(1-\beta_{n}\right)\left\|G v_{n}-W_{n} \tilde{v}_{n}\right\|^{2}-2 \mu \alpha_{n}\left\langle\widetilde{A}_{2} p, x_{n+1}-p\right\rangle \\
\leq & \beta_{n}\left\|\tilde{z}_{n}-p\right\|^{2}+\left(1-\beta_{n}\right)\left\|v_{n}-p\right\|^{2}+2 \rho_{n}\left\|\widetilde{A}_{1} v_{n}\right\|\left\|\tilde{v}_{n}-p\right\| \\
& +2 \mu \alpha_{n}\left\|\widetilde{A}_{2} p\right\|\left\|x_{n+1}-p\right\| \\
\leq & \beta_{n}\left[\left\|z_{n}-\tilde{p}\right\|^{2}+v_{1}\left(v_{1}-2 \zeta_{1}\right)\left\|A_{1} z_{n}-A_{1} \tilde{p}\right\|^{2}\right]+\left(1-\beta_{n}\right)\left\|v_{n}-p\right\|^{2} \\
& +2 \rho_{n}\left\|\widetilde{A}_{1} v_{n}\right\|\left\|\tilde{v}_{n}-p\right\|+2 \mu \alpha_{n}\left\|\widetilde{A}_{2} p\right\|\left\|x_{n+1}-p\right\| \\
\leq & \beta_{n}\left[\left\|v_{n}-p\right\|^{2}+v_{2}\left(v_{2}-2 \zeta_{2}\right)\left\|A_{2} v_{n}-A_{2} p\right\|^{2}+v_{1}\left(v_{1}-2 \zeta_{1}\right)\left\|A_{1} z_{n}-A_{1} \tilde{p}\right\|^{2}\right] \\
& +\left(1-\beta_{n}\right)\left\|v_{n}-p\right\|^{2}+2 \rho_{n}\left\|\widetilde{A}_{1} v_{n}\right\|\left\|\tilde{v}_{n}-p\right\|+2 \mu \alpha_{n}\left\|\widetilde{A}_{2} p\right\|\left\|x_{n+1}-p\right\| \\
= & \left\|v_{n}-p\right\|^{2}+\beta_{n}\left[v_{2}\left(v_{2}-2 \zeta_{2}\right)\left\|A_{2} v_{n}-A_{2} p\right\|^{2}+v_{1}\left(v_{1}-2 \zeta_{1}\right)\left\|A_{1} z_{n}-A_{1} \tilde{p}\right\|^{2}\right] \\
& +2 \rho_{n}\left\|\widetilde{A}_{1} v_{n}\right\|\left\|\tilde{v}_{n}-p\right\|+2 \mu \alpha_{n}\left\|\widetilde{A}_{2} p\right\|\left\|x_{n+1}-p\right\| \\
\leq & \left\|x_{n}-p\right\|^{2}+\beta_{n}\left[v_{2}\left(v_{2}-2 \zeta_{2}\right)\left\|A_{2} v_{n}-A_{2} p\right\|^{2}+v_{1}\left(v_{1}-2 \zeta_{1}\right)\left\|A_{1} z_{n}-A_{1} \tilde{p}\right\|^{2}\right] \\
& +2 \rho_{n}\left\|\widetilde{A}_{1} v_{n}\right\|\left\|\tilde{v}_{n}-p\right\|+2 \mu \alpha_{n}\left\|\widetilde{A}_{2} p\right\|\left\|x_{n+1}-p\right\|,
\end{aligned}
$$

which leads to

$$
\begin{aligned}
& \beta_{n}\left[v_{2}\left(2 \zeta_{2}-v_{2}\right)\left\|A_{2} v_{n}-A_{2} p\right\|^{2}+v_{1}\left(2 \zeta_{1}-v_{1}\right)\left\|A_{1} z_{n}-A_{1} \tilde{p}\right\|^{2}\right] \\
& \leq\left\|x_{n}-p\right\|^{2}-\left\|x_{n+1}-p\right\|^{2}+2 \rho_{n}\left\|\widetilde{A}_{1} v_{n}\right\|\left\|\tilde{v}_{n}-p\right\|+2 \mu \alpha_{n}\left\|\widetilde{A}_{2} p\right\|\left\|x_{n+1}-p\right\| \\
& \leq\left\|x_{n}-x_{n+1}\right\|\left(\left\|x_{n}-p\right\|+\left\|x_{n+1}-p\right\|\right)+2 \rho_{n}\left\|\widetilde{A}_{1} v_{n}\right\|\left\|\tilde{v}_{n}-p\right\|+2 \mu \alpha_{n}\left\|\widetilde{A}_{2} p\right\|\left\|x_{n+1}-p\right\| .
\end{aligned}
$$

Since $\alpha_{n} \rightarrow 0, \rho_{n} \rightarrow 0,\left\|x_{n+1}-x_{n}\right\| \rightarrow 0$ and $\left\{x_{n}\right\},\left\{v_{n}\right\},\left\{\tilde{v}_{n}\right\}$ are bounded sequences, it follows from $v_{k} \in\left(0,2 \zeta_{k}\right), k=1,2$ and $\left\{\beta_{n}\right\}_{n=1}^{\infty} \subset[a, b] \subset(0,1)$ that

$$
\lim _{n \rightarrow \infty}\left\|A_{2} v_{n}-A_{2} p\right\|=0 \text { and } \lim _{n \rightarrow \infty}\left\|A_{1} z_{n}-A_{1} \tilde{p}\right\|=0
$$

Also, in terms of the firm nonexpansivity of $T_{v_{k}}^{\Theta_{k}}$ and the $\zeta_{k}$-inverse strong monotonicity of $A_{k}$ for $k=1,2$, we obtain from $v_{k} \in\left(0,2 \zeta_{k}\right), k=1,2$ and (3.4)-(3.5) that

$$
\begin{aligned}
\left\|z_{n}-\tilde{p}\right\|^{2} & =\left\|T_{v_{2}}^{\Theta_{2}}\left(I-v_{2} A_{2}\right) v_{n}-T_{v_{2}}^{\Theta_{2}}\left(I-v_{2} A_{2}\right) p\right\|^{2} \\
& \leq\left\langle\left(I-v_{2} A_{2}\right) v_{n}-\left(I-v_{2} A_{2}\right) p, z_{n}-\tilde{p}\right\rangle
\end{aligned}
$$




$$
\begin{aligned}
= & \frac{1}{2}\left[\left\|\left(I-v_{2} A_{2}\right) v_{n}-\left(I-v_{2} A_{2}\right) p\right\|^{2}+\left\|z_{n}-\tilde{p}\right\|^{2}\right. \\
& \left.-\left\|\left(I-v_{2} A_{2}\right) v_{n}-\left(I-v_{2} A_{2}\right) p-\left(z_{n}-\tilde{p}\right)\right\|^{2}\right] \\
\leq & \frac{1}{2}\left[\left\|v_{n}-p\right\|^{2}+\left\|z_{n}-\tilde{p}\right\|^{2}-\left\|\left(v_{n}-z_{n}\right)-v_{2}\left(A_{2} v_{n}-A_{2} p\right)-(p-\tilde{p})\right\|^{2}\right] \\
\leq & \frac{1}{2}\left[\left\|x_{n}-p\right\|^{2}+\left\|z_{n}-\tilde{p}\right\|^{2}-\left\|\left(v_{n}-z_{n}\right)-(p-\tilde{p})\right\|^{2}\right. \\
& \left.+2 v_{2}\left\langle\left(v_{n}-z_{n}\right)-(p-\tilde{p}), A_{2} v_{n}-A_{2} p\right\rangle-v_{2}^{2}\left\|A_{2} v_{n}-A_{2} p\right\|^{2}\right],
\end{aligned}
$$

and

$$
\begin{aligned}
\left\|\tilde{z}_{n}-p\right\|^{2}= & \left\|T_{v_{1}}^{\Theta_{1}}\left(I-v_{1} A_{1}\right) z_{n}-T_{v_{1}}^{\Theta_{1}}\left(I-v_{1} A_{1}\right) \tilde{p}\right\|^{2} \\
\leq & \left\langle\left(I-v_{1} A_{1}\right) z_{n}-\left(I-v_{1} A_{1}\right) \tilde{p}, \tilde{z}_{n}-p\right\rangle \\
= & \frac{1}{2}\left[\left\|\left(I-v_{1} A_{1}\right) z_{n}-\left(I-v_{1} A_{1}\right) \tilde{p}\right\|^{2}+\left\|\tilde{z}_{n}-p\right\|^{2}\right. \\
& \left.-\left\|\left(I-v_{1} A_{1}\right) z_{n}-\left(I-v_{1} A_{1}\right) \tilde{p}-\left(\tilde{z}_{n}-p\right)\right\|^{2}\right] \\
\leq & \frac{1}{2}\left[\left\|z_{n}-\tilde{p}\right\|^{2}+\left\|\tilde{z}_{n}-p\right\|^{2}-\left\|\left(z_{n}-\tilde{z}_{n}\right)+(p-\tilde{p})\right\|^{2}\right. \\
& \left.+2 v_{1}\left\langle A_{1} z_{n}-A_{1} \tilde{p},\left(z_{n}-\tilde{z}_{n}\right)+(p-\tilde{p})\right\rangle-v_{1}^{2}\left\|A_{1} z_{n}-A_{1} \tilde{p}\right\|^{2}\right] \\
\leq & \frac{1}{2}\left[\left\|x_{n}-p\right\|^{2}+\left\|\tilde{z}_{n}-p\right\|^{2}-\left\|\left(z_{n}-\tilde{z}_{n}\right)+(p-\tilde{p})\right\|^{2}\right. \\
& \left.+2 v_{1}\left\langle A_{1} z_{n}-A_{1} \tilde{p},\left(z_{n}-\tilde{z}_{n}\right)+(p-\tilde{p})\right\rangle\right] .
\end{aligned}
$$

Thus, we have

$$
\begin{aligned}
\left\|z_{n}-\tilde{p}\right\|^{2} \leq & \left\|x_{n}-p\right\|^{2}-\left\|\left(v_{n}-z_{n}\right)-(p-\tilde{p})\right\|^{2}+2 v_{2}\left\langle\left(v_{n}-z_{n}\right)-(p-\tilde{p}), A_{2} v_{n}-A_{2} p\right\rangle \\
& -v_{2}^{2}\left\|A_{2} v_{n}-A_{2} p\right\|^{2},
\end{aligned}
$$

and

$$
\left\|\tilde{z}_{n}-p\right\|^{2} \leq\left\|x_{n}-p\right\|^{2}-\left\|\left(z_{n}-\tilde{z}_{n}\right)+(p-\tilde{p})\right\|^{2}+2 v_{1}\left\|A_{1} z_{n}-A_{1} \tilde{p}\right\|\left\|\left(z_{n}-\tilde{z}_{n}\right)+(p-\tilde{p})\right\| .
$$

Consequently, from (3.4), (3.5), (3.11) and (3.23) it follows that

$$
\begin{aligned}
&\left\|x_{n+1}-p\right\|^{2} \\
& \leq \beta_{n}\left\|G v_{n}-p\right\|^{2}+\left(1-\beta_{n}\right)\left(\left\|v_{n}-p\right\|^{2}-2 \rho_{n}\left\langle\widetilde{A}_{1} v_{n}, \tilde{v}_{n}-p\right\rangle\right) \\
&-\beta_{n}\left(1-\beta_{n}\right)\left\|G v_{n}-W_{n} \tilde{v}_{n}\right\|^{2}-2 \mu \alpha_{n}\left\langle\widetilde{A}_{2} p, x_{n+1}-p\right\rangle \\
& \leq \beta_{n}\left\|\tilde{z}_{n}-p\right\|^{2}+\left(1-\beta_{n}\right)\left\|v_{n}-p\right\|^{2}+2 \rho_{n}\left\|\widetilde{A}_{1} v_{n}\right\|\left\|\tilde{v}_{n}-p\right\|+2 \mu \alpha_{n}\left\|\widetilde{A}_{2} p\right\|\left\|x_{n+1}-p\right\| \\
& \leq \beta_{n}\left\|z_{n}-\tilde{p}\right\|^{2}+\left(1-\beta_{n}\right)\left\|v_{n}-p\right\|^{2}+2 \rho_{n}\left\|\widetilde{A}_{1} v_{n}\right\|\left\|\tilde{v}_{n}-p\right\|+2 \mu \alpha_{n}\left\|\widetilde{A}_{2} p\right\|\left\|x_{n+1}-p\right\| \\
& \leq \beta_{n}\left[\left\|x_{n}-p\right\|^{2}-\left\|\left(v_{n}-z_{n}\right)-(p-\tilde{p})\right\|^{2}+2 v_{2}\left\langle\left(v_{n}-z_{n}\right)-(p-\tilde{p}), A_{2} v_{n}-A_{2} p\right\rangle\right. \\
&\left.-v_{2}^{2}\left\|A_{2} v_{n}-A_{2} p\right\|^{2}\right]+\left(1-\beta_{n}\right)\left\|x_{n}-p\right\|^{2}+2 \rho_{n}\left\|\widetilde{A}_{1} v_{n}\right\|\left\|\tilde{v}_{n}-p\right\|+2 \mu \alpha_{n}\left\|\widetilde{A}_{2} p\right\|\left\|x_{n+1}-p\right\| \\
& \leq \beta_{n}\left[\left\|x_{n}-p\right\|^{2}-\left\|\left(v_{n}-z_{n}\right)-(p-\tilde{p})\right\|^{2}+2 v_{2}\left\|\left(v_{n}-z_{n}\right)-(p-\tilde{p})\right\|\left\|A_{2} v_{n}-A_{2} p\right\|\right] \\
&+\left(1-\beta_{n}\right)\left\|x_{n}-p\right\|^{2}+2 \rho_{n}\left\|\widetilde{A}_{1} v_{n}\right\|\left\|\tilde{v}_{n}-p\right\|+2 \mu \alpha_{n}\left\|\widetilde{A}_{2} p\right\|\left\|x_{n+1}-p\right\|
\end{aligned}
$$




$$
\begin{aligned}
\leq & \left\|x_{n}-p\right\|^{2}-\beta_{n}\left\|\left(v_{n}-z_{n}\right)-(p-\tilde{p})\right\|^{2}+2 v_{2}\left\|\left(v_{n}-z_{n}\right)-(p-\tilde{p})\right\|\left\|A_{2} v_{n}-A_{2} p\right\| \\
& +2 \rho_{n}\left\|\widetilde{A}_{1} v_{n}\right\|\left\|\tilde{v}_{n}-p\right\|+2 \mu \alpha_{n}\left\|\widetilde{A}_{2} p\right\|\left\|x_{n+1}-p\right\|,
\end{aligned}
$$

which leads to

$$
\begin{aligned}
\beta_{n} & \left\|\left(v_{n}-z_{n}\right)-(p-\tilde{p})\right\|^{2} \\
\leq & \left\|x_{n}-p\right\|^{2}-\left\|x_{n+1}-p\right\|^{2}+2 v_{2}\left\|\left(v_{n}-z_{n}\right)-(p-\tilde{p})\right\|\left\|A_{2} v_{n}-A_{2} p\right\| \\
& +2 \rho_{n}\left\|\widetilde{A}_{1} v_{n}\right\|\left\|\tilde{v}_{n}-p\right\|+2 \mu \alpha_{n}\left\|\widetilde{A}_{2} p\right\|\left\|x_{n+1}-p\right\| \\
\leq & \left\|x_{n}-x_{n+1}\right\|\left(\left\|x_{n}-p\right\|+\left\|x_{n+1}-p\right\|\right)+2 v_{2}\left\|\left(v_{n}-z_{n}\right)-(p-\tilde{p})\right\|\left\|A_{2} v_{n}-A_{2} p\right\| \\
& +2 \rho_{n}\left\|\widetilde{A}_{1} v_{n}\right\|\left\|\tilde{v}_{n}-p\right\|+2 \mu \alpha_{n}\left\|\widetilde{A}_{2} p\right\|\left\|x_{n+1}-p\right\|,
\end{aligned}
$$

Since $\alpha_{n} \rightarrow 0, \rho_{n} \rightarrow 0,\left\|x_{n+1}-x_{n}\right\| \rightarrow 0$ and $\left\{x_{n}\right\},\left\{v_{n}\right\},\left\{\tilde{v}_{n}\right\},\left\{z_{n}\right\}$ are bounded sequences, it follows from (3.22) and $\left\{\beta_{n}\right\} \subset[a, b] \subset(0,1)$ that

$$
\lim _{n \rightarrow \infty}\left\|\left(v_{n}-z_{n}\right)-(p-\tilde{p})\right\|=0 .
$$

Furthermore, from (3.4), (3.11) and (3.24) it follows that

$$
\begin{aligned}
&\left\|x_{n+1}-p\right\|^{2} \\
& \leq \beta_{n}\left\|G v_{n}-p\right\|^{2}+\left(1-\beta_{n}\right)\left(\left\|v_{n}-p\right\|^{2}-2 \rho_{n}\left\langle\widetilde{A}_{1} v_{n}, \tilde{v}_{n}-p\right\rangle\right) \\
&-\beta_{n}\left(1-\beta_{n}\right)\left\|G v_{n}-W_{n} \tilde{v}_{n}\right\|^{2}-2 \mu \alpha_{n}\left\langle\widetilde{A}_{2} p, x_{n+1}-p\right\rangle \\
& \leq \beta_{n}\left\|\tilde{z}_{n}-p\right\|^{2}+\left(1-\beta_{n}\right)\left\|v_{n}-p\right\|^{2}+2 \rho_{n}\left\|\widetilde{A}_{1} v_{n}\right\|\left\|\tilde{v}_{n}-p\right\|+2 \mu \alpha_{n}\left\|\widetilde{A}_{2} p\right\|\left\|x_{n+1}-p\right\| \\
& \leq \beta_{n}\left[\left\|x_{n}-p\right\|^{2}-\left\|\left(z_{n}-\tilde{z}_{n}\right)+(p-\tilde{p})\right\|^{2}+2 v_{1}\left\|A_{1} z_{n}-A_{1} \tilde{p}\right\|\left\|\left(z_{n}-\tilde{z}_{n}\right)+(p-\tilde{p})\right\|\right] \\
&+\left(1-\beta_{n}\right)\left\|x_{n}-p\right\|^{2}+2 \rho_{n}\left\|\widetilde{A}_{1} v_{n}\right\|\left\|\tilde{v}_{n}-p\right\|+2 \mu \alpha_{n}\left\|\widetilde{A}_{2} p\right\|\left\|x_{n+1}-p\right\| \\
& \leq\left\|x_{n}-p\right\|^{2}-\beta_{n}\left\|\left(z_{n}-\tilde{z}_{n}\right)+(p-\tilde{p})\right\|^{2}+2 v_{1}\left\|A_{1} z_{n}-A_{1} \tilde{p}\right\|\left\|\left(z_{n}-\tilde{z}_{n}\right)+(p-\tilde{p})\right\| \\
&+2 \rho_{n}\left\|\widetilde{A}_{1} v_{n}\right\|\left\|\tilde{v}_{n}-p\right\|+2 \mu \alpha_{n}\left\|\widetilde{A}_{2} p\right\|\left\|x_{n+1}-p\right\|,
\end{aligned}
$$

which yields

$$
\begin{aligned}
\beta_{n} & \left\|\left(z_{n}-\tilde{z}_{n}\right)+(p-\tilde{p})\right\|^{2} \\
\leq & \left\|x_{n}-p\right\|^{2}-\left\|x_{n+1}-p\right\|^{2}+2 v_{1}\left\|A_{1} z_{n}-A_{1} \tilde{p}\right\|\left\|\left(z_{n}-\tilde{z}_{n}\right)+(p-\tilde{p})\right\| \\
& +2 \rho_{n}\left\|\widetilde{A}_{1} v_{n}\right\|\left\|\tilde{v}_{n}-p\right\|+2 \mu \alpha_{n}\left\|\widetilde{A}_{2} p\right\|\left\|x_{n+1}-p\right\| \\
\leq & \left\|x_{n}-x_{n+1}\right\|\left(\left\|x_{n}-p\right\|+\left\|x_{n+1}-p\right\|\right)+2 v_{1}\left\|A_{1} z_{n}-A_{1} \tilde{p}\right\|\left\|\left(z_{n}-\tilde{z}_{n}\right)+(p-\tilde{p})\right\| \\
& +2 \rho_{n}\left\|\tilde{A}_{1} v_{n}\right\|\left\|\tilde{v}_{n}-p\right\|+2 \mu \alpha_{n}\left\|\tilde{A}_{2} p\right\|\left\|x_{n+1}-p\right\| .
\end{aligned}
$$

Since $\alpha_{n} \rightarrow 0, \rho_{n} \rightarrow 0,\left\|x_{n+1}-x_{n}\right\| \rightarrow 0$ and $\left\{x_{n}\right\},\left\{v_{n}\right\},\left\{\tilde{v}_{n}\right\},\left\{z_{n}\right\},\left\{\tilde{z}_{n}\right\}$ are bounded sequences, it follows from (3.22) and $\left\{\beta_{n}\right\} \subset[a, b] \subset(0,1)$ that

$$
\lim _{n \rightarrow \infty}\left\|\left(z_{n}-\tilde{z}_{n}\right)+(p-\tilde{p})\right\|=0 .
$$


Note that

$$
\left\|v_{n}-\tilde{z}_{n}\right\| \leq\left\|\left(v_{n}-z_{n}\right)-(p-\tilde{p})\right\|+\left\|\left(z_{n}-\tilde{z}_{n}\right)+(p-\tilde{p})\right\| .
$$

Hence from (3.25) and (3.26) we get

$$
\lim _{n \rightarrow \infty}\left\|v_{n}-\tilde{z}_{n}\right\|=\lim _{n \rightarrow \infty}\left\|v_{n}-G v_{n}\right\|=0
$$

Also, observe that $\left\|\tilde{v}_{n}-x_{n}\right\| \leq\left\|v_{n}-x_{n}\right\|+\rho_{n}\left\|\widetilde{A}_{1} v_{n}\right\|$ and

$$
\left\|y_{n}-x_{n}\right\| \leq\left\|x_{n+1}-x_{n}\right\|+\mu \alpha_{n}\left\|\widetilde{A}_{2} y_{n}\right\|
$$

Hence from (3.21), $\alpha_{n} \rightarrow 0, \rho_{n} \rightarrow 0$ and $\left\|x_{n+1}-x_{n}\right\| \rightarrow 0$ we obtain that

$$
\lim _{n \rightarrow \infty}\left\|\tilde{v}_{n}-x_{n}\right\|=0 \quad \text { and } \quad \lim _{n \rightarrow \infty}\left\|y_{n}-x_{n}\right\|=0 .
$$

So, from (3.12), (3.27) and $\rho_{n} \rightarrow 0$ we deduce that

$$
\begin{aligned}
\left\|W_{n} \tilde{v}_{n}-\tilde{v}_{n}\right\| & \leq\left\|W_{n} \tilde{v}_{n}-G v_{n}\right\|+\left\|G v_{n}-v_{n}\right\|+\left\|v_{n}-\tilde{v}_{n}\right\| \\
& =\left\|W_{n} \tilde{v}_{n}-G v_{n}\right\|+\left\|G v_{n}-v_{n}\right\|+\rho_{n}\left\|\widetilde{A}_{1} v_{n}\right\| \rightarrow 0 \quad \text { as } n \rightarrow \infty .
\end{aligned}
$$

In addition, it is clear that

$$
\left\|\tilde{v}_{n}-W \tilde{v}_{n}\right\| \leq\left\|\tilde{v}_{n}-W_{n} \tilde{v}_{n}\right\|+\left\|W_{n} \tilde{v}_{n}-W \tilde{v}_{n}\right\| .
$$

Thus, we conclude from Remark ??, (3.29) and the boundedness of $\left\{\tilde{v}_{n}\right\}$ that

$$
\lim _{n \rightarrow \infty}\left\|\tilde{v}_{n}-W \tilde{v}_{n}\right\|=0
$$

Step 4. We prove that $\omega_{w}\left(x_{n}\right) \subset \Omega$.

Indeed, since $H$ is reflexive and $\left\{x_{n}\right\}$ is bounded, there exists at least a weak convergence subsequence of $\left\{x_{n}\right\}$. Hence it is known that $\omega_{w}\left(x_{n}\right) \neq \varnothing$. Now, take an arbitrary $w \in \omega_{w}\left(x_{n}\right)$. Then there exists a subsequence $\left\{x_{n_{i}}\right\}$ of $\left\{x_{n}\right\}$ such that $x_{n_{i}} \rightarrow w$. From (3.15), (3.19), (3.21) and (3.28), we have that $u_{n_{i}} \rightarrow w, v_{n_{i}} \rightarrow w, \tilde{v}_{n_{i}} \rightarrow w$ and $\Lambda_{n_{i}}^{m} u_{n_{i}} \rightarrow w$ for $m=1,2, \ldots, N$. Utilizing Lemma 2.3, we deduce from $v_{n_{i}} \rightarrow w$ and $\tilde{v}_{n_{i}} \rightarrow w$, (3.27) and (3.20) that $w \in \operatorname{SGEP}(G)$ and $w \in \operatorname{Fix}(W)=\cap_{n=1}^{\infty} \operatorname{Fix}\left(T_{n}\right)$ (due to Lemma 2.5). Next, we prove that $w \in \cap_{m=1}^{N} \mathrm{I}\left(B_{m}, R_{m}\right)$. As a matter of fact, since $B_{m}$ is $\eta_{m}$-inverse strongly monotone, $B_{m}$ is a monotone and Lipschitz continuous mapping. It follows from Lemma 2.13 that $R_{m}+B_{m}$ is maximal monotone. Let $(\nu, g) \in G\left(R_{m}+B_{m}\right)$, i.e., $g-B_{m} v \in R_{m} \nu$. Again, since $\Lambda_{n}^{m} u_{n}=J_{R_{m}, \lambda_{m, n}}\left(I-\lambda_{m, n} B_{m}\right) \Lambda_{n}^{m-1} u_{n}, n \geq$ $1, m \in\{1,2, \ldots, N\}$, we have

$$
\Lambda_{n}^{m-1} u_{n}-\lambda_{m, n} B_{m} \Lambda_{n}^{m-1} u_{n} \in\left(I+\lambda_{m, n} R_{m}\right) \Lambda_{n}^{m} u_{n}
$$


that is,

$$
\frac{1}{\lambda_{m, n}}\left(\Lambda_{n}^{m-1} u_{n}-\Lambda_{n}^{m} u_{n}-\lambda_{m, n} B_{m} \Lambda_{n}^{m-1} u_{n}\right) \in R_{m} \Lambda_{n}^{m} u_{n}
$$

In terms of the monotonicity of $R_{m}$, we get

$$
\left\langle v-\Lambda_{n}^{m} u_{n}, g-B_{m} v-\frac{1}{\lambda_{m, n}}\left(\Lambda_{n}^{m-1} u_{n}-\Lambda_{n}^{m} u_{n}-\lambda_{m, n} B_{m} \Lambda_{n}^{m-1} u_{n}\right)\right\rangle \geq 0
$$

and hence

$$
\begin{aligned}
\langle v & \left.-\Lambda_{n}^{m} u_{n}, g\right\rangle \\
& \geq\left\langle v-\Lambda_{n}^{m} u_{n}, B_{m} v+\frac{1}{\lambda_{m, n}}\left(\Lambda_{n}^{m-1} u_{n}-\Lambda_{n}^{m} u_{n}-\lambda_{m, n} B_{m} \Lambda_{n}^{m-1} u_{n}\right)\right\rangle \\
& =\left\langle v-\Lambda_{n}^{m} u_{n}, B_{m} v-B_{m} \Lambda_{n}^{m} u_{n}+B_{m} \Lambda_{n}^{m} u_{n}-B_{m} \Lambda_{n}^{m-1} u_{n}+\frac{1}{\lambda_{m, n}}\left(\Lambda_{n}^{m-1} u_{n}-\Lambda_{n}^{m} u_{n}\right)\right\rangle \\
& \geq\left\langle v-\Lambda_{n}^{m} u_{n}, B_{m} \Lambda_{n}^{m} u_{n}-B_{m} \Lambda_{n}^{m-1} u_{n}\right\rangle+\left\langle v-\Lambda_{n}^{m} u_{n}, \frac{1}{\lambda_{m, n}}\left(\Lambda_{n}^{m-1} u_{n}-\Lambda_{n}^{m} u_{n}\right)\right\rangle .
\end{aligned}
$$

In particular,

$$
\left\langle v-\Lambda_{n_{i}}^{m} u_{n_{i}}, g\right\rangle \geq\left\langle\nu-\Lambda_{n_{i}}^{m} u_{n_{i}}, B_{m} \Lambda_{n_{i}}^{m} u_{n_{i}}-B_{m} \Lambda_{n_{i}}^{m-1} u_{n_{i}}\right\rangle+\left\langle v-\Lambda_{n_{i}}^{m} u_{n_{i}}, \frac{1}{\lambda_{m, n_{i}}}\left(\Lambda_{n_{i}}^{m-1} u_{n_{i}}-\Lambda_{n_{i}}^{m} u_{n_{i}}\right)\right\rangle .
$$

Since $\left\|\Lambda_{n}^{m} u_{n}-\Lambda_{n}^{m-1} u_{n}\right\| \rightarrow 0$ (due to (3.19)) and $\left\|B_{m} \Lambda_{n}^{m} u_{n}-B_{m} \Lambda_{n}^{m-1} u_{n}\right\| \rightarrow 0$ (due to the Lipschitz continuity of $\left.B_{m}\right)$, we conclude from $\Lambda_{n_{i}}^{m} u_{n_{i}} \rightarrow w$ and $\left\{\lambda_{i, n}\right\} \subset\left[a_{i}, b_{i}\right] \subset\left(0,2 \eta_{i}\right)$ that

$$
\lim _{i \rightarrow \infty}\left\langle v-\Lambda_{n_{i}}^{m} u_{n_{i}}, g\right\rangle=\langle v-w, g\rangle \geq 0 .
$$

It follows from the maximal monotonicity of $B_{m}+R_{m}$ that $0 \in\left(R_{m}+B_{m}\right) w$, i.e., $w \in \mathrm{I}\left(B_{m}, R_{m}\right)$. Therefore, $w \in \cap_{m=1}^{N} \mathrm{I}\left(B_{m}, R_{m}\right)$.

Next, we show that $w \in \operatorname{GMEP}(\Theta, \varphi, A)$. In fact, from $u_{n}=S_{r_{n}}^{(\Theta, \varphi)}\left(I-r_{n} A\right) x_{n}$, we know that

$$
\Theta\left(u_{n}, y\right)+\varphi(y)-\varphi\left(u_{n}\right)+\left\langle A x_{n}, y-u_{n}\right\rangle+\frac{1}{r_{n}}\left\langle K^{\prime}\left(u_{n}\right)-K^{\prime}\left(x_{n}\right), y-u_{n}\right\rangle \geq 0, \quad \forall y \in C .
$$

From (H2) it follows that

$$
\varphi(y)-\varphi\left(u_{n}\right)+\left\langle A x_{n}, y-u_{n}\right\rangle+\frac{1}{r_{n}}\left\langle K^{\prime}\left(u_{n}\right)-K^{\prime}\left(x_{n}\right), y-u_{n}\right\rangle \geq \Theta\left(y, u_{n}\right), \quad \forall y \in C .
$$

Replacing $n$ by $n_{i}$, we have

$$
\varphi(y)-\varphi\left(u_{n_{i}}\right)+\left\langle A x_{n_{i}}, y-u_{n_{i}}\right\rangle+\left\langle\frac{K^{\prime}\left(u_{n_{i}}\right)-K^{\prime}\left(x_{n_{i}}\right)}{r_{n_{i}}}, y-u_{n_{i}}\right\rangle \geq \Theta\left(y, u_{n_{i}}\right), \quad \forall y \in C .
$$

Put $u_{t}=t y+(1-t) w$ for all $t \in(0,1]$ and $y \in C$. Then, from (3.31) we have $\left\langle u_{t}-u_{n_{i}}, A u_{t}\right\rangle$ 


$$
\begin{aligned}
\geq & \left\langle u_{t}-u_{n_{i}}, A u_{t}\right\rangle-\varphi\left(u_{t}\right)+\varphi\left(u_{n_{i}}\right)-\left\langle u_{t}-u_{n_{i}}, A x_{n_{i}}\right\rangle-\left\langle\frac{K^{\prime}\left(u_{n_{i}}\right)-K^{\prime}\left(x_{n_{i}}\right)}{r_{n_{i}}}, u_{t}-u_{n_{i}}\right\rangle+\Theta\left(u_{t}, u_{n_{i}}\right) \\
\geq & \left\langle u_{t}-u_{n_{i}}, A u_{t}-A u_{n_{i}}\right\rangle+\left\langle u_{t}-u_{n_{i}}, A u_{n_{i}}-A x_{n_{i}}\right\rangle-\varphi\left(u_{t}\right)+\varphi\left(u_{n_{i}}\right) \\
& -\left\langle\frac{K^{\prime}\left(u_{n_{i}}\right)-K^{\prime}\left(x_{n_{i}}\right)}{r_{n_{i}}}, u_{t}-u_{n_{i}}\right\rangle+\Theta\left(u_{t}, u_{n_{i}}\right) .
\end{aligned}
$$

Since $\left\|u_{n_{i}}-x_{n_{i}}\right\| \rightarrow 0$ as $i \rightarrow \infty$, we deduce from the Lipschitz continuity of $A$ and $K^{\prime}$ that $\left\|A u_{n_{i}}-A x_{n_{i}}\right\| \rightarrow 0$ and $\left\|K^{\prime}\left(u_{n_{i}}\right)-K^{\prime}\left(x_{n_{i}}\right)\right\| \rightarrow 0$ as $i \rightarrow \infty$. Further, from the monotonicity of $A$, we have $\left\langle u_{t}-u_{n_{i}}, A u_{t}-A u_{n_{i}}\right\rangle \geq 0$. So, from (H4), the weakly lower semicontinuity of $\varphi, \frac{K^{\prime}\left(u_{n_{i}}\right)-K^{\prime}\left(x_{n_{i}}\right)}{r_{n_{i}}} \rightarrow 0$ and $u_{n_{i}} \rightarrow w$, we have

$$
\left\langle u_{t}-w, A u_{t}\right\rangle \geq-\varphi\left(u_{t}\right)+\varphi(w)+\Theta\left(u_{t}, w\right), \quad \text { as } i \rightarrow \infty
$$

From (H1), (H4) and (3.32) we also have

$$
\begin{aligned}
0 & =\Theta\left(u_{t}, u_{t}\right)+\varphi\left(u_{t}\right)-\varphi\left(u_{t}\right) \\
& \leq t \Theta\left(u_{t}, y\right)+(1-t) \Theta\left(u_{t}, w\right)+t \varphi(y)+(1-t) \varphi(w)-\varphi\left(u_{t}\right) \\
& =t\left[\Theta\left(u_{t}, y\right)+\varphi(y)-\varphi\left(u_{t}\right)\right]+(1-t)\left[\Theta\left(u_{t}, w\right)+\varphi(w)-\varphi(w)-\varphi\left(u_{t}\right)\right] \\
& \leq t\left[\Theta\left(u_{t}, y\right)+\varphi(y)-\varphi\left(u_{t}\right)\right]+(1-t)\left\langle u_{t}-w, A u_{t}\right\rangle \\
& =t\left[\Theta\left(u_{t}, y\right)+\varphi(y)-\varphi\left(u_{t}\right)\right]+(1-t) t\left\langle y-w, A u_{t}\right\rangle,
\end{aligned}
$$

and hence

$$
0 \leq \Theta\left(u_{t}, y\right)+\varphi(y)-\varphi\left(u_{t}\right)+(1-t)\left\langle y-w, A u_{t}\right\rangle .
$$

Letting $t \rightarrow 0$, we have, for each $y \in C$,

$$
0 \leq \Theta(w, y)+\varphi(y)-\varphi(w)+\langle A w, y-w\rangle
$$

This implies that $w \in \operatorname{GMEP}(\Theta, \varphi, A)$. Therefore, $w \in \cap_{n=1}^{\infty} \operatorname{Fix}\left(T_{n}\right) \cap \operatorname{GMEP}(\Theta, \varphi, A) \cap \operatorname{SGEP}(G) \cap$ $\cap_{i=1}^{N} \mathrm{I}\left(B_{i}, R_{i}\right):=\Omega$. This shows that $\omega_{w}\left(x_{n}\right) \subset \Omega$.

Step 5. We prove that $\omega_{w}\left(x_{n}\right) \subset \operatorname{VI}\left(\Omega, \widetilde{A}_{1}\right)$ provided $\left\|x_{n}-y_{n}\right\|=o\left(\rho_{n}\right)$ additionally.

Indeed, take an arbitrary $w \in \omega_{w}\left(x_{n}\right)$. Then there exists a subsequence $\left\{x_{n_{i}}\right\}$ of $\left\{x_{n}\right\}$ such that $x_{n_{i}} \rightarrow w$. Since $A_{1}$ is $\alpha$-inverse strongly monotone, from (3.1), (3.4) and (3.5) we conclude that for all $p \in \Omega$

$$
\begin{aligned}
\left\|y_{n}-p\right\|^{2} & =\left\|\beta_{n}\left(G v_{n}-p\right)+\left(1-\beta_{n}\right)\left(W_{n} \tilde{v}_{n}-p\right)\right\|^{2} \\
& \leq \beta_{n}\left\|G v_{n}-p\right\|^{2}+\left(1-\beta_{n}\right)\left\|W_{n} \tilde{v}_{n}-p\right\|^{2} \\
& \leq \beta_{n}\left\|v_{n}-p\right\|^{2}+\left(1-\beta_{n}\right)\left\|\tilde{v}_{n}-p\right\|^{2} \\
& =\beta_{n}\left\|v_{n}-p\right\|^{2}+\left(1-\beta_{n}\right)\left\|v_{n}-p-\rho_{n} \widetilde{A}_{1} v_{n}\right\|^{2} \\
& \leq \beta_{n}\left\|v_{n}-p\right\|^{2}+\left(1-\beta_{n}\right)\left[\left\|v_{n}-p\right\|^{2}-2 \rho_{n}\left\langle\widetilde{A}_{1} v_{n}, \tilde{v}_{n}-p\right\rangle\right]
\end{aligned}
$$




$$
\begin{aligned}
= & \beta_{n}\left\|v_{n}-p\right\|^{2}+\left(1-\beta_{n}\right)\left[\left\|v_{n}-p\right\|^{2}-2 \rho_{n}\left(\left\langle\widetilde{A}_{1} v_{n}, v_{n}-p\right\rangle+\left\langle\widetilde{A}_{1} v_{n}, \tilde{v}_{n}-v_{n}\right\rangle\right)\right] \\
= & \beta_{n}\left\|v_{n}-p\right\|^{2}+\left(1-\beta_{n}\right)\left[\left\|v_{n}-p\right\|^{2}-2 \rho_{n}\left(\left\langle\widetilde{A}_{1} v_{n}-\widetilde{A}_{1} p, v_{n}-p\right\rangle\right.\right. \\
& \left.\left.+\left\langle\widetilde{A}_{1} p, v_{n}-p\right\rangle+\left\langle\widetilde{A}_{1} v_{n}, \tilde{v}_{n}-v_{n}\right\rangle\right)\right] \\
= & \left\|v_{n}-p\right\|^{2}-2 \rho_{n}\left(1-\beta_{n}\right)\left(\left\langle\widetilde{A}_{1} v_{n}-\widetilde{A}_{1} p, v_{n}-p\right\rangle+\left\langle\widetilde{A}_{1} p, v_{n}-p\right\rangle\right. \\
& \left.+\left\langle\widetilde{A}_{1} v_{n}, \tilde{v}_{n}-v_{n}\right\rangle\right) \\
\leq & \left\|x_{n}-p\right\|^{2}-2 \rho_{n}\left(1-\beta_{n}\right)\left\langle\widetilde{A}_{1} p, v_{n}-p\right\rangle+2 \rho_{n}\left(1-\beta_{n}\right)\left\|\widetilde{A}_{1} v_{n}\right\|\left\|\tilde{v}_{n}-v_{n}\right\|,
\end{aligned}
$$

which implies that

$$
\begin{aligned}
\left\langle\widetilde{A}_{1} p, v_{n}-p\right\rangle & \leq \frac{1}{2 \rho_{n}\left(1-\beta_{n}\right)}\left(\left\|x_{n}-p\right\|^{2}-\left\|y_{n}-p\right\|^{2}\right)+\left\|\tilde{A}_{1} v_{n}\right\|\left\|\tilde{v}_{n}-v_{n}\right\| \\
& \leq \frac{\left\|x_{n}-y_{n}\right\|}{2 \rho_{n}\left(1-\beta_{n}\right)}\left(\left\|x_{n}-p\right\|+\left\|y_{n}-p\right\|\right)+\rho_{n}^{2}\left\|\tilde{A}_{1} v_{n}\right\|^{2} .
\end{aligned}
$$

So, from $\rho_{n} \rightarrow 0$ and the assumption $\left\|x_{n}-y_{n}\right\|=o\left(\rho_{n}\right)$, we get

$$
\limsup _{n \rightarrow \infty}\left\langle\widetilde{A}_{1} p, v_{n}-p\right\rangle \leq 0 .
$$

Thus, it follows from (3.21) that for all $p \in \Omega$

$$
\begin{aligned}
\left\langle\widetilde{A}_{1} p, w-p\right\rangle & =\lim _{i \rightarrow \infty}\left\langle\widetilde{A}_{1} p, x_{n_{i}}-p\right\rangle \\
& \leq \limsup _{n \rightarrow \infty}\left\langle\widetilde{A}_{1} p, x_{n}-p\right\rangle \\
& =\limsup _{n \rightarrow \infty}\left(\left\langle\widetilde{A}_{1} p, v_{n}-p\right\rangle+\left\langle\widetilde{A}_{1} p, x_{n}-v_{n}\right\rangle\right) \\
& =\limsup _{n \rightarrow \infty}\left\langle\widetilde{A}_{1} p, v_{n}-p\right\rangle \\
& \leq 0,
\end{aligned}
$$

that is,

$$
\left\langle\widetilde{A}_{1} p, p-w\right\rangle \geq 0, \quad \forall p \in \Omega .
$$

Since $\widetilde{A}_{1}$ is $\alpha$-inverse strongly monotone, by Minty's Lemma [4] we know that (3.34) is equivalent to the VIP

$$
\left\langle\widetilde{A}_{1} w, p-w\right\rangle \geq 0, \quad \forall p \in \Omega .
$$

This shows that $w \in \operatorname{VI}\left(\Omega, \widetilde{A}_{1}\right)$. Therefore, $\omega_{w}\left(x_{n}\right) \subset \operatorname{VI}\left(\Omega, \widetilde{A}_{1}\right)$.

Theorem 3.2. Assume that all the conditions in Theorem 3.1 are satisfied. Then we have

(i) $\left\{x_{n}\right\}$ converges strongly to a point $u^{*} \in \Omega$, which is a unique solution of the VIP

$$
\left\langle\widetilde{A}_{2} u^{*}, p-u^{*}\right\rangle \geq 0, \quad \forall p \in \Omega ;
$$

(ii) $\left\{x_{n}\right\}$ converges strongly to a unique solution of THVI (1.9) provided $\left\|x_{n}-y_{n}\right\|=o\left(\theta_{n}\right)$ additionally. 
Proof. Since $\widetilde{A}_{2}$ is $\beta$-strongly monotone and $L$-Lipschitz continuous, there exists a unique solution $u^{*} \in \Omega$ of the VIP

$$
\left\langle\widetilde{A}_{2} u^{*}, p-u^{*}\right\rangle \geq 0, \quad \forall p \in \Omega \text {. }
$$

Now, let us show that

$$
\limsup _{n \rightarrow \infty}\left\langle\widetilde{A}_{2} u^{*}, u^{*}-x_{n}\right\rangle \leq 0 .
$$

Since $\left\{x_{n}\right\}$ is bounded, we may assume, without loss of generality, that there exists a subsequence $\left\{x_{n_{i}}\right\}$ of $\left\{x_{n}\right\}$ such that $x_{n_{i}} \rightarrow w$ and

$$
\limsup _{n \rightarrow \infty}\left\langle\widetilde{A}_{2} u^{*}, u^{*}-x_{n}\right\rangle=\lim _{i \rightarrow \infty}\left\langle\widetilde{A}_{2} u^{*}, u^{*}-x_{n_{i}}\right\rangle=\left\langle\widetilde{A}_{2} u^{*}, u^{*}-w\right\rangle .
$$

In terms of Theorem 3.1 (ii), we know that $w \in \omega_{w}\left(x_{n}\right) \subset \Omega$. So, from (3.36) it follows that

$$
\limsup _{n \rightarrow \infty}\left\langle\widetilde{A}_{2} u^{*}, u^{*}-x_{n}\right\rangle=\left\langle\widetilde{A}_{2} u^{*}, u^{*}-w\right\rangle \leq 0 .
$$

Next, let us show that $\lim _{n \rightarrow \infty}\left\|x_{n}-u^{*}\right\|=0$. In fact, utilizing Lemma 2.1, from (3.1) and (3.33) with $p=u^{*}$ we get

$$
\begin{aligned}
\| & x_{n+1}-u^{*} \|^{2} \\
= & \left\|\left(I-\mu \alpha_{n} \widetilde{A}_{2}\right) y_{n}-u^{*}\right\|^{2} \\
= & \left\|\left(I-\mu \alpha_{n} \widetilde{A}_{2}\right) y_{n}-\left(I-\mu \alpha_{n} \widetilde{A}_{2}\right) u^{*}+\left(I-\mu \alpha_{n} \widetilde{A}_{2}\right) u^{*}-u^{*}\right\|^{2} \\
\leq & \left\|\left(I-\mu \alpha_{n} \widetilde{A}_{2}\right) y_{n}-\left(I-\mu \alpha_{n} \widetilde{A}_{2}\right) u^{*}\right\|^{2}-2 \mu \alpha_{n}\left\langle\widetilde{A}_{2} u^{*}, x_{n+1}-u^{*}\right\rangle \\
\leq & \left(1-\alpha_{n} \tau\right)\left\|y_{n}-u^{*}\right\|^{2}-2 \mu \alpha_{n}\left\langle\widetilde{A}_{2} u^{*}, x_{n+1}-u^{*}\right\rangle \\
\leq & \left(1-\alpha_{n} \tau\right)\left[\left\|x_{n}-u^{*}\right\|^{2}-2 \rho_{n}\left(1-\beta_{n}\right)\left\langle\widetilde{A}_{1} u^{*}, v_{n}-u^{*}\right\rangle\right. \\
& \left.+2 \rho_{n}\left(1-\beta_{n}\right)\left\|\widetilde{A}_{1} v_{n}\right\|\left\|\tilde{v}_{n}-v_{n}\right\|\right]-2 \mu \alpha_{n}\left\langle\widetilde{A}_{2} u^{*}, x_{n+1}-u^{*}\right\rangle \\
\leq & \left(1-\alpha_{n} \tau\right)\left\|x_{n}-u^{*}\right\|^{2}+2 \rho_{n}\left\|\widetilde{A}_{1} u^{*}\right\|\left\|v_{n}-u^{*}\right\|+2 \rho_{n}^{2}\left\|\widetilde{A}_{1} v_{n}\right\|^{2}-2 \mu \alpha_{n}\left\langle\widetilde{A}_{2} u^{*}, x_{n+1}-u^{*}\right\rangle \\
= & \left(1-\alpha_{n} \tau\right)\left\|x_{n}-u^{*}\right\|^{2}+\alpha_{n} \tau \cdot \frac{2}{\tau}\left\{\frac{\rho_{n}}{\alpha_{n}}\left\|\widetilde{A}_{1} u^{*}\right\|\left\|v_{n}-u^{*}\right\|+\frac{\rho_{n}^{2}}{\alpha_{n}}\left\|\widetilde{A}_{1} v_{n}\right\|^{2}+\mu\left\langle\widetilde{A}_{2} u^{*}, u^{*} \mid !-x_{n+1}\right\rangle\right\}
\end{aligned}
$$

where $\tau=1-\sqrt{1-\mu\left(2 \beta-\mu L^{2}\right)}$.

Since $\sum_{n=1}^{\infty} \alpha_{n}=\infty, \lim _{n \rightarrow \infty} \frac{\rho_{n}}{\alpha_{n}}=0$ and $\limsup _{n \rightarrow \infty}\left\langle\widetilde{A}_{2} u^{*}, u^{*}-x_{n+1}\right\rangle \leq 0$ (due to (3.37)), we deduce that $\sum_{n=1}^{\infty} \alpha_{n} \tau=\infty$, and

$$
\limsup _{n \rightarrow \infty} \frac{2}{\tau}\left\{\frac{\rho_{n}}{\alpha_{n}}\left\|\widetilde{A}_{1} u^{*}\right\|\left\|v_{n}-u^{*}\right\|+\frac{\rho_{n}^{2}}{\alpha_{n}}\left\|\widetilde{A}_{1} v_{n}\right\|^{2}+\mu\left\langle\widetilde{A}_{2} u^{*}, u^{*}-x_{n+1}\right\rangle\right\} \leq 0 \text {. }
$$

Therefore, applying Lemma 2.8 to (3.38) we infer that $\lim _{n \rightarrow \infty}\left\|x_{n}-u^{*}\right\|=0$.

Finally, we prove that $\lim _{n \rightarrow \infty}\left\|x_{n}-x^{*}\right\|=0$ provided $\left\|x_{n}-y_{n}\right\|=o\left(\alpha_{n}\right)$ additionally, where $\left\{x^{*}\right\}=\operatorname{VI}\left(\operatorname{VI}\left(\Omega, \widetilde{A}_{1}\right), \widetilde{A}_{2}\right)$. 
Indeed, first of all, let us show that $\omega_{w}\left(x_{n}\right)=\left\{x^{*}\right\}$. As a matter of fact, take an arbitrary $w \in \omega_{w}\left(x_{n}\right)$. Then there exists a subsequence $\left\{x_{n_{j}}\right\}$ of $\left\{x_{n}\right\}$ such that $x_{n_{j}} \rightarrow w$. Moreover, by Theorem 3.1 (iii) we know that $w \in \omega_{w}\left(x_{n}\right) \subset \operatorname{VI}\left(\Omega, \widetilde{A}_{1}\right)$. Utilizing Lemmas 2.1 and 2.7, from (3.1) and (3.33) we deduce that for all $p \in \operatorname{VI}\left(\Omega, \widetilde{A}_{1}\right)$

$$
\begin{aligned}
&\left\|x_{n+1}-p\right\|^{2} \\
&=\left\|\left(I-\mu \alpha_{n} \widetilde{A}_{2}\right) y_{n}-p\right\|^{2} \\
&=\left\|\left(I-\mu \alpha_{n} \widetilde{A}_{2}\right) y_{n}-\left(I-\mu \alpha_{n} \widetilde{A}_{2}\right) p+\left(I-\mu \alpha_{n} \widetilde{A}_{2}\right) p-p\right\|^{2} \\
& \leq\left\|\left(I-\mu \alpha_{n} \widetilde{A}_{2}\right) y_{n}-\left(I-\mu \alpha_{n} \widetilde{A}_{2}\right) p\right\|^{2}-2 \mu \alpha_{n}\left\langle\widetilde{A}_{2} p, x_{n+1}-p\right\rangle \\
& \leq\left(1-\alpha_{n} \tau\right)\left\|y_{n}-p\right\|^{2}-2 \mu \alpha_{n}\left\langle\widetilde{A}_{2} p, x_{n+1}-p\right\rangle \\
& \leq\left(1-\alpha_{n} \tau\right)\left[\left\|x_{n}-p\right\|^{2}-2 \rho_{n}\left(1-\beta_{n}\right)\left\langle\widetilde{A}_{1} p, v_{n}-p\right\rangle+2 \rho_{n}\left(1-\beta_{n}\right)\left\|\widetilde{A}_{1} v_{n}\right\|\left\|\tilde{v}_{n}-v_{n}\right\|\right] \\
&-2 \mu \alpha_{n}\left\langle\widetilde{A}_{2} p, x_{n+1}-p\right\rangle \\
& \leq\left\|x_{n}-p\right\|^{2}+2 \rho_{n}\left\|\widetilde{A}_{1} p\right\|\left\|v_{n}-p\right\|+2 \rho_{n}^{2}\left\|\widetilde{A}_{1} v_{n}\right\|^{2}-2 \mu \alpha_{n}\left\langle\widetilde{A}_{2} p, x_{n+1}-p\right\rangle,
\end{aligned}
$$

where $\tau=1-\sqrt{1-\mu\left(2 \beta-\mu L^{2}\right)}$. So, it follows that

$$
\begin{aligned}
& \left\langle\widetilde{A}_{2} p, x_{n+1}-p\right\rangle \\
& \leq \frac{1}{2 \mu \alpha_{n}}\left(\left\|x_{n}-p\right\|^{2}-\left\|x_{n+1}-p\right\|^{2}\right)+\frac{\rho_{n}}{\mu \alpha_{n}}\left[\left\|\widetilde{A}_{1} p\right\|\left\|v_{n}-p\right\|+\rho_{n}\left\|\widetilde{A}_{1} v_{n}\right\|^{2}\right] \\
& \leq \frac{\left\|x_{n}-x_{n+1}\right\|}{2 \mu \alpha_{n}}\left(\left\|x_{n}-p\right\|+\left\|x_{n+1}-p\right\|\right)+\frac{\rho_{n}}{\mu \alpha_{n}}\left[\left\|\widetilde{A}_{1} p\right\|\left\|v_{n}-p\right\|+\rho_{n}\left\|\widetilde{A}_{1} v_{n}\right\|^{2}\right] .
\end{aligned}
$$

Since $\alpha_{n} \rightarrow 0, \rho_{n}=o\left(\alpha_{n}\right)$ and $\left\|x_{n+1}-x_{n}\right\|=o\left(\rho_{n}\right)$, we find that

$$
\lim _{n \rightarrow \infty} \frac{\left\|x_{n+1}-x_{n}\right\|}{\alpha_{n}}=\lim _{n \rightarrow \infty} \frac{\left\|x_{n+1}-x_{n}\right\|}{\rho_{n}} \cdot \frac{\rho_{n}}{\alpha_{n}}=0 .
$$

Hence we conclude from (3.40) that for all $p \in \operatorname{VI}\left(\Omega, \widetilde{A}_{1}\right)$

$$
\begin{aligned}
\left\langle\widetilde{A}_{2} p, w-p\right\rangle & =\lim _{j \rightarrow \infty}\left\langle\widetilde{A}_{2} p, x_{n_{j}}-p\right\rangle \\
& \leq \limsup _{n \rightarrow \infty}\left\langle\widetilde{A}_{2} p, x_{n}-p\right\rangle \\
& =\limsup _{n \rightarrow \infty}\left(\left\langle\widetilde{A}_{2} p, x_{n}-x_{n+1}\right\rangle+\left\langle\widetilde{A}_{2} p, x_{n+1}-p\right\rangle\right) \\
& =\limsup _{n \rightarrow \infty}\left\langle\widetilde{A}_{2} p, x_{n+1}-p\right\rangle \\
& \leq 0,
\end{aligned}
$$

that is,

$$
\left\langle\widetilde{A}_{2} p, p-w\right\rangle \geq 0, \quad \forall p \in \operatorname{VI}\left(\Omega, \widetilde{A}_{1}\right) .
$$


Since $\widetilde{A}_{2}$ is $\beta$-strongly monotone and $L$-Lipschitz continuous, by Minty's Lemma [4] we know that (3.41) is equivalent to the VIP

$$
\left\langle\widetilde{A}_{2} w, p-w\right\rangle \geq 0, \quad \forall p \in \operatorname{VI}\left(\Omega, \widetilde{A}_{1}\right) .
$$

This shows that $w \in \operatorname{VI}\left(\operatorname{VI}\left(\Omega, \widetilde{A}_{1}\right), \widetilde{A}_{2}\right)$. Taking into account $\left\{x^{*}\right\}=\operatorname{VI}\left(\operatorname{VI}\left(\Omega, \widetilde{A}_{1}\right), \widetilde{A}_{2}\right)$, we know that $w=x^{*}$. Thus, $\omega_{w}\left(x_{n}\right)=\left\{x^{*}\right\}$; that is, $x_{n} \rightarrow x^{*}$.

Next we prove that $\lim _{n \rightarrow \infty}\left\|x_{n}-x^{*}\right\|=0$. As a matter of fact, utilizing (3.39) with $p=x^{*}$, we get

$$
\begin{aligned}
\| & x_{n+1}-x^{*} \|^{2} \\
\leq & \left(1-\alpha_{n} \tau\right)\left[\left\|x_{n}-x^{*}\right\|^{2}-2 \rho_{n}\left(1-\beta_{n}\right)\left\langle\widetilde{A}_{1} x^{*}, v_{n}-x^{*}\right\rangle+2 \rho_{n}\left(1-\beta_{n}\right)\left\|\widetilde{A}_{1} v_{n}\right\|\left\|\tilde{v}_{n}-v_{n}\right\|\right] \\
& -2 \mu \alpha_{n}\left\langle\widetilde{A}_{2} x^{*}, x_{n+1}-x^{*}\right\rangle \\
\leq & \left(1-\alpha_{n} \tau\right)\left\|x_{n}-x^{*}\right\|^{2}+2 \rho_{n}\left\|\widetilde{A}_{1} x^{*}\right\|\left\|v_{n}-x^{*}\right\|+2 \rho_{n}^{2}\left\|\widetilde{A}_{1} v_{n}\right\|^{2}-2 \mu \alpha_{n}\left\langle\widetilde{A}_{2} x^{*}, x_{n+1}-x^{*}\right\rangle \\
= & \left(1-\alpha_{n} \tau\right)\left\|x_{n}-x^{*}\right\|^{2}+\alpha_{n} \tau \cdot \frac{2}{\tau}\left[\frac{\rho_{n}}{\alpha_{n}}\left\|\widetilde{A}_{1} x^{*}\right\|\left\|v_{n}-x^{*}\right\|+\frac{\rho_{n}^{2}}{\alpha_{n}}\left\|\widetilde{A}_{1} v_{n}\right\|^{2}-\mu\left\langle\widetilde{A}_{2} x^{*}, x_{n+1}-x^{*}\right\rangle\right] .(3.4
\end{aligned}
$$

Since $\sum_{n=1}^{\infty} \alpha_{n}=\infty, \lim _{n \rightarrow \infty} \frac{\rho_{n}}{\alpha_{n}}=0$ and $\lim _{n \rightarrow \infty}\left\langle\widetilde{A}_{2} x^{*}, x^{*}-x_{n+1}\right\rangle=0$ (due to $x_{n} \rightarrow x^{*}$ ), we deduce that $\sum_{n=1}^{\infty} \alpha_{n} \tau=\infty$, and

$$
\lim _{n \rightarrow \infty} \frac{2}{\tau}\left[\frac{\rho_{n}}{\alpha_{n}}\left\|\widetilde{A}_{1} x^{*}\right\|\left\|v_{n}-x^{*}\right\|+\frac{\rho_{n}^{2}}{\alpha_{n}}\left\|\widetilde{A}_{1} v_{n}\right\|^{2}-\mu\left\langle\widetilde{A}_{2} x^{*}, x_{n+1}-x^{*}\right\rangle\right]=0 .
$$

Therefore, applying Lemma 2.8 to (3.43) we infer that $\lim _{n \rightarrow \infty}\left\|x_{n}-x^{*}\right\|=0$. This completes the proof.

Remark 3.1. It is obvious that our iterative scheme (3.1) is very different from Ceng, Ansari and Schaible iterative one (1.4), Yao, Liou and Marino iterative one (1.8) and Zeng, Wong and Yao iterative one in Algorithm ZWY. Here, the two-step iterative scheme in [22, Algorithm 3.2] is extended to develop our four-step iterative scheme (3.1) for the THVI (1.9) by combining Korpelevich's extragradient method, hybrid steepest-descent method and Mann's iteration method. The problem of finding a point $x^{*} \in \cap_{n=1}^{\infty} \operatorname{Fix}\left(T_{n}\right) \cap \operatorname{GMEP}(\Theta, \varphi, A) \cap \operatorname{SGEP}(G)$ in [25] is extended to the more general problem of finding a point $x^{*} \in \cap_{n=1}^{\infty} \operatorname{Fix}\left(T_{n}\right) \cap \operatorname{GMEP}(\Theta, \varphi, A) \cap$ $\cap_{i=1}^{N} \mathrm{I}\left(B_{i}, R_{i}\right) \cap \operatorname{SGEP}(G)$, which is involved in THVI (1.9). It is worth pointing out that under the lack of the assumptions similar to those in [19, Theorem 3.2], e.g., $\left\{x_{n}\right\}$ is bounded, $\operatorname{Fix}(T) \cap \operatorname{int} C \neq \varnothing$ and $\|x-T x\| \geq k \operatorname{Dist}(x, \operatorname{Fix}(T)), \forall x \in C$ for some $k>0$, the sequence $\left\{x_{n}\right\}$ generated by (3.1) converges strongly to a point $u^{*} \in \cap_{n=1}^{\infty} \operatorname{Fix}\left(T_{n}\right) \cap \operatorname{GMEP}(\Theta, \varphi, A) \cap \cap_{i=1}^{N} \mathrm{I}\left(B_{i}, R_{i}\right) \cap$ $\operatorname{SGEP}(G)=: \Omega$, which is a unique solution of the VIP: $\left\langle\widetilde{A}_{2} u^{*}, p-u^{*}\right\rangle \geq 0, \forall p \in \Omega$.

Remark 3.2. Our Theorems 3.1 and 3.2 improve, extend, supplement and develop Yao, Liou and Marino [19, Theorems 3.1 and 3.2] and Zeng, Wong and Yao [22, Theorem 3.2] in the following aspects: 
(a) Our THVI (1.9) with the unique solution $x^{*} \in \Omega$ satisfying

$$
x^{*}=P_{\cap_{n=1}^{\infty} \operatorname{Fix}\left(T_{n}\right) \cap \operatorname{GMEP}(\Theta, \varphi, A) \cap \cap_{i=1}^{N} \mathrm{I}\left(B_{i}, R_{i}\right) \cap \operatorname{SGEP}(G)}\left(I-\widetilde{A}_{1}\right) x^{*}
$$

is more general than the problem of finding a point $\tilde{x} \in C$ satisfying $\tilde{x}=P_{\operatorname{Fix}(T)} S \tilde{x}$ in [19] and than the problem of finding a point $x^{*} \in \cap_{i=1}^{N} \operatorname{Fix}\left(T_{i}\right)$ satisfying $x^{*}=P_{\cap_{i=1}^{N} \operatorname{Fix}\left(T_{i}\right)}(I-$ $\left.A_{1}\right) x^{*}$ in [22, Theorem 3.2]. It is worth pointing out that $S$ is nonexpansive if and only if the complement $I-S$ is $\frac{1}{2}$-inverse strongly monotone; see [27].

(b) Our four-step iterative scheme (3.1) for THVI (1.9) is more flexible, more advantageous and more subtle than Zeng, Wong and Yao's two-step iterative one in [22, Algorithm 3.2] and than Yao, Liou and Marino's two-step iterative one (1.8) because it can be used to solve several kinds of problems, e.g., the THVI, the hierarchical VIP and the problem of finding a common point of four sets: $\cap_{n=1}^{\infty} \operatorname{Fix}\left(T_{n}\right), \operatorname{GMEP}(\Theta, \varphi, A), \cap_{i=1}^{N} \mathrm{I}\left(B_{i}, R_{i}\right)$ and $\operatorname{SGEP}(G)$. In addition, it also drops the crucial requirements that $\operatorname{Fix}(T) \cap \operatorname{int} C \neq \varnothing$ and $\|x-T x\| \geq k \operatorname{Dist}(x, \operatorname{Fix}(T)), \forall x \in C$ for some $k>0$ in [19, Theorem $3.2(\mathrm{v})]$.

(c) The argument techniques in our Theorems 3.1 and 3.2 are very different from the argument ones in [19, Theorems 3.1 and 3.2] and from the argument ones in [22, Theorem 3.2] because we use the $W$-mapping approach to fixed points of infinitely many nonexpansive mappings $\left\{T_{n}\right\}_{n=1}^{\infty}$ (see Lemmas 2.4 and 2.5), the properties of resolvent operators and maximal monotone mappings (see Proposition 2.2, Remarks 2.1, 2.4 and Lemmas $2.9-2.13)$, the fixed point equation $x^{*}=T_{v_{1}}^{\Theta_{1}}\left(I-v_{1} A_{1}\right) T_{v_{2}}^{\Theta_{2}}\left(I-v_{2} A_{2}\right) x^{*}$ equivalent to the SGEP (1.4) (see Proposition 2.3) and the contractive coefficient estimates for the contractions associating with nonexpansive mappings (see Lemma 2.7).

(d) Compared with the restrictions on the parameter sequences of [19, Theorem 3.2] and [22, Theorem 3.2], respectively, the hypotheses (v)-(vi) in our Theorem 3.1 are additionally added because our Theorem 3.1 involves the quite complex problem, i.e., the THVI (1.9) (over the set $\cap_{n=1}^{\infty} \operatorname{Fix}\left(T_{n}\right)$ ) with constraints of several problems: GMEP (1.2), finitely many variational inclusions and SGEP(1.4).

\section{References}

[1] H. K. Xu and T. H. Kim, Convergence of hybrid steepest-descent methods for variational inequalities, J. Optim. Theory. Appl., 119 (1) (2003), 185-201.

[2] G. M. Korpelevich, The extragradient method for finding saddle points and other problems, Matecon. 12 (1976) 747-756.

[3] J. G. O'Hara, P. Pillay and H. K. Xu, Iterative approaches to convex feasibility problems in Banach spaces, Nonlinear Anal., 64 (9) (2006), 2022-2042.

[4] K. Goebel and W. A. Kirk, Topics on Metric Fixed-Point Theory, Cambridge University Press, Cambridge, England, 1990. 
[5] R. T. Rockafellar, Monotone operators and the proximal point algorithms, SIAM J. Control Optim., 14 (1976), 877-898.

[6] V. Barbu, Nonlinear Semigroups and Differential Equations in Banach Spaces, Noordhoff, 1976.

[7] L. C. Zeng, S. M. Guu and J. C. Yao, Characterization of H-monotone operators with applications to variational inclusions, Comput. Math. Appl., 50 (3-4) (2005), 329-337.

[8] L. C. Ceng, Q. H. Ansari and J. C. Yao, An extragradient method for solving split feasibility and fixed point problems, Comput. Math. Appl., 64 (4) (2012), 633-642.

[9] L. C. Ceng, S. M. Guu and J. C. Yao, Finding common solutions of a variational inequality, a general system of variational inequalities, and a fixed-point problem via a hybrid extragradient method, Fixed Point Theory Appl. 2011, Art. ID 626159, 22 pp.

[10] L. C. Ceng, C. Y. Wang and J. C. Yao, Strong convergence theorems by a relaxed extragradient method for a general system of variational inequalities, Math. Methods Oper. Res., 67 (2008), 375-390.

[11] L. C. Zeng and J. C. Yao, Strong convergence theorem by an extragradient method for fixed point problems and variational inequality problems, Taiwan. J. Math., 10 (5) (2006), 1293-1303.

[12] L. C. Ceng, Q. H. Ansari and J. C. Yao, Relaxed extragradient methods for finding minimum-norm solutions of the split feasibility problem, Nonlinear Anal., 75 (4) (2012), 2116-2125.

[13] J. L. Lions, Quelques Méthodes de Résolution des Problèmes aux Limites Non Linéaires, Dunod, Paris, 1969.

[14] L. C. Ceng, Q. H. Ansari, M. M. Wong and J. C. Yao, Mann type hybrid extragradient method for variational inequalities, variational inclusions and fixed point problems, Fixed Point Theory, 13 (2) (2012), 403-422.

[15] Y. Yao, M. A. Noor, S. Zainab and Y. C. Liou, Mixed equilibrium problems and optimization problems, J. Math. Anal. Anal. Appl., 354 (2009), 319-329.

[16] H. Iiduka, Strong convergence for an iterative method for the triple-hierarchical constrained optimization problem, Nonlinear Anal., 71 (2009), 1292-1297.

[17] H. Iiduka, Iterative algorithm for solving triple-hierarchical constrained optimization problem, J. Optim. Theory Appl., 148 (2011), 580-592.

[18] N. Nadezhkina and W. Takahashi, Strong convergence theorem by a hybrid method for nonexpansive mappings and Lipschitz-continuous monotone mappings, SIAM J. Optim., 16 (2006), 1230-1241.

[19] Y. Yao, Y. C. Liou and G. Marino, Two-step iterative algorithms for hierarchical fixed point problems and variational inequality problems, J. Appl. Math. Comput., 31 (1-2) (2009), 433-445.

[20] G. Cai and S. Q. Bu, Strong and weak convergence theorems for general mixed equilibrium problems and variational inequality problems and fixed point problems in Hilbert spaces, J. Comput. Appl. Math., 247 (2013), 34-52.

[21] L. C. Ceng and J. C. Yao, A hybrid iterative scheme for mixed equilibrium problems and fixed point problems, J. Comput. Appl. Math., 214 (2008), 186-201.

[22] L. C. Zeng, M. M. Wong and J. C. Yao, Strong convergence of relaxed hybrid steepest-descent methods for triple hierarchical constrained optimization, Fixed Point Theory Appl., 2012, 2012:29, 24 pp.

[23] J. W. Peng and J. C. Yao, A new hybrid-extragradient method for generalized mixed equilibrium problems, fixed point problems and variational inequality problems, Taiwan. J. Math., 12 (2008), 1401-1432.

[24] L. C. Ceng and J. C. Yao, A relaxed extragradient-like method for a generalized mixed equilibrium problem, a general system of generalized equilibria and a fixed point problem, Nonlinear Anal., 72 (2010), 1922-1937.

[25] L. C. Ceng, Q. H. Ansari and S. Schaible, Hybrid extragradient-like methods for generalized mixed equilibrium problems, system of generalized equilibrium problems and optimization problems, J. Glob. Optim., 53 (2012), 69-96.

[26] L. C. Ceng, S. M. Guu and J. C. Yao, Hybrid iterative method for finding common solutions of generalized mixed equilibrium and fixed point problems, Fixed Point Theory Appl., 2012, 2012:92, 19pp.

[27] L. C. Ceng, S. M. Guu and J. C. Yao, Iterative algorithm for finding approximate solutions of mixed quasivariational-like inclusions, Comput. Math. Appl., 56 (2008), 942-952.

[28] L. C. Ceng, Q. H. Ansari and J. C. Yao, Relaxed extragradient iterative methods for variational inequalities, Appl. Math. Comput., 218 (2011), 1112-1123. 
[29] L. C. Ceng and S. Al-Homidan, Algorithms of common solutions for generalized mixed equilibria, variational inclusions, and constrained convex minimization, Abstr. Appl. Anal., 2014, Art. ID 132053, 25pp.

[30] Y. Yao, Y. C. Liou and S. M. Kang, Approach to common elements of variational inequality problems and fixed point problems via a relaxed extragradient method, Comput. Math. Appl., 59 (2010), 3472-3480.

[31] Y. Yao, Y. C. Liou and J. C. Yao, Convergence theorem for equilibrium problems and fixed point problems of infinite family of nonexpansive mappings, Fixed Point Theory Appl., 2007 (2007) Article ID 64363, 12pp.

[32] L. C. Ceng, S. M. Guu and J. C. Yao, Iterative approximation of solutions for a class of completely generalized set-valued quasi-variational inclusions, Comput. Math. Appl., 56 (2008) 978-987.

[33] N. J. Huang, A new completely general class of variational inclusions with noncompact valued mappings, Comput. Math. Appl., 35 (10) (1998), 9-14.

[34] L. C. Ceng, Q. H. Ansari, N. C. Wong and J. C. Yao, An extragradient-like approximation method for variational inequalities and fixed point problems, Fixed Point Theory Appl., 2011, 2011:22, 18 pp.

[35] L. C. Ceng, M. Teboulle, J. C. Yao, Weak convergence of an iterative method for pseudomonotone variational inequalities and fixed point problems, J. Optim. Theory Appl., 146 (2010), 19-31.

[36] L. C. Ceng and A. Petrusel, Relaxed extragradient-like method for general system of generalized mixed equilibria and fixed point problem, Taiwan. J. Math., 16 (2) (2012), 445-478.

Department of Mathematics, Shanghai Normal University, and Scientific Computing Key Laboratory of Shanghai Universities, Shanghai 200234, China.

E-mail: zenglc@hotmail.com

Center for Fundamental Science, Kaohsiung Medical University, Kaohsiung 807, Taiwan; and Department of Applied Mathematics, National Sun Yat-sen University, Kaohsiung, Taiwan 804; and Department of Mathematics, King Abdulaziz University, P.O. Box 80203, Jeddah 21589, Saudi Arabia.

E-mail: yaojc@kmu.edu.tw 